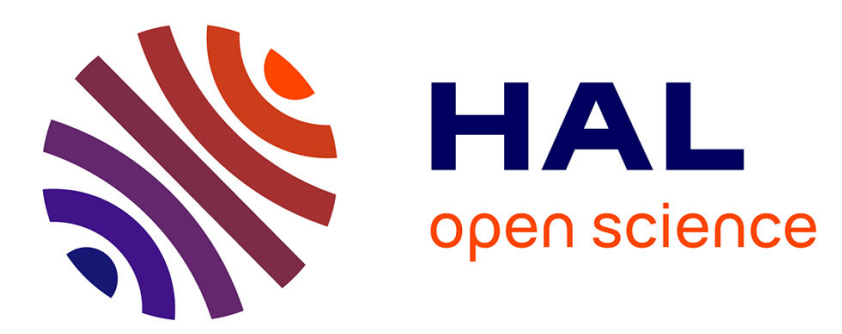

\title{
Multiaxial fatigue models for short glass fibre reinforced polyamide. Part II: Fatigue life estimation
}

\author{
Antoine Launay, Habibou Maitournam, Yann Marco, Ida Raoult
}

\section{To cite this version:}

Antoine Launay, Habibou Maitournam, Yann Marco, Ida Raoult. Multiaxial fatigue models for short glass fibre reinforced polyamide. Part II: Fatigue life estimation. International Journal of Fatigue, 2013, 47, pp $390-406$, issn $=$ "0142-1123", url = "http://www.sciencedirect.com/science/article/pii/S014211231. 10.1016/j.ijfatigue.2012.09.015 . hal-00778281

\section{HAL Id: hal-00778281}

https: / hal-polytechnique.archives-ouvertes.fr/hal-00778281

Submitted on 19 Jan 2013

HAL is a multi-disciplinary open access archive for the deposit and dissemination of scientific research documents, whether they are published or not. The documents may come from teaching and research institutions in France or abroad, or from public or private research centers.
L'archive ouverte pluridisciplinaire HAL, est destinée au dépôt et à la diffusion de documents scientifiques de niveau recherche, publiés ou non, émanant des établissements d'enseignement et de recherche français ou étrangers, des laboratoires publics ou privés. 


\title{
Multiaxial fatigue models for short glass fiber reinforced polyamide. Part II: Fatigue life estimation.
}

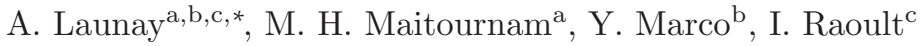 \\ ${ }^{a}$ Laboratoire de Mécanique des Solides (CNRS UMR 7649), École polytechnique, 91128 Palaiseau, France \\ ${ }^{b}$ Laboratoire Brestois de Mécanique et des Systèmes (EA 4325 ENSTA Bretagne/UBO/ENIB), 2 rue François Verny, 29806 \\ Brest Cedex 9, France \\ ${ }^{c}$ PSA Peugeot Citroën (Direction Scientifique et des Technologies Futures), Route de Gisy, 78943 Vélizy-Villacoublay Cedex, \\ France
}

\begin{abstract}
Components made of short fiber reinforced thermoplastics are increasingly used in the automotive industry, and more and more frequently subjected to fatigue loadings during their service life. The determination of a predictive fatigue criterion is therefore a serious issue for the designers, and requires the knowledge of the local mechanical response. As the cyclic behaviour of polymeric material is reckoned to be highly non-linear, even at room temperature, an accurate constitutive model is a preliminary step for confident fatigue design.

Constitutive equations for the cyclic behaviour, developed and validated by the authors in Part I of this paper [Launay et al., Int J Fatigue, 2012], are applied to the mechanical analysis of fatigue campaigns carried out by Klimkeit et al. and De Monte et al. on specimens made out of polyamide 66 reinforced with $35 \mathrm{wt} \%$ of short glass fibres. Both studies are performed at room temperature, with material conditioned at the equilibrium with air containing $50 \%$ of relative humidity (RH50) or dry-as-moulded (DAM).

Post-processing the cyclic response in steady-state allows the comparison of several fatigue criteria. The fatigue databases involve various loadings, including the study of multiaxiality and mean-stress effects on different microstructures. Among all physical quantities, the dissipated energy density per cycle $\Delta W_{\text {diss }}$ displays the best correlation with the fatigue life.
\end{abstract}

Keywords: PA66-GF35, fibre orientation distribution, multiaxial fatigue, energy criterion

\section{Introduction}

\subsection{Industrial context and motivations}

In order to reduce their environmental impact, carmakers wish to substitute heavy metallic parts by lightweight composite structures. Short glass fibre reinforced (SGFR) thermoplastics are a cost-efficient solution which combines sufficient stiffness for many structural components and a large freedom of shapes

\footnotetext{
*Corresponding author. Tel.: (+33/0)15759 41 66; fax: (+33/0)1 41243256

Email address: antoine.launay@mpsa.com (A. Launay)
} 
provided by injection molding. The choices of glass fibres and polyamide matrices are usual and motivated by cost and thermal stability respectively.

These materials have long been used by the automotive industry for components which do not undergo much mechanical loading. They are now increasingly used to make structural parts such as intake manifolds or engine mounts, which are subjected to complex and repeated mechanical loading as well as environmental conditions such as heat and humidity. Therefore, the need for a method to design those components against fatigue failure has become a serious issue during the last years, when different authors began addressing the problem. In this paper which is the second part of [1], Klimkeit's [2, 3] and De Monte's [4] recent fatigue experiments give the basis for a comparative study of different fatigue criteria.

Part I of this work [1] describes the adopted approach for fatigue design. It relies on the uncoupling between the damage evolution and the cyclic behaviour. The first step regards the simulation of the material response under cyclic loading, until a steady-state is reached, and is the topic of Part I. The second step, detailed in this paper (Part II), is devoted to the identification of a physical quantity giving the best correlation with the number of cycles to failure. The relationship between these two quantities, called fatigue life model, is applied to the cyclic response in the steady-state regime to estimate the fatigue duration.

\subsection{Crack initiation mechanisms}

Some propagation mechanisms of SGFR thermoplastics are investigated in the literature from fractographic studies. Horst et al. [5, 6] proposed two different damage scenarios depending on the ductile or fragile behaviour of the thermoplastic matrix. Noda et al. [7] agreed with these results, the temperature controlling the matrix behaviour in their work. However, the authors assume that microvoid occurring at fibre ends is the first step of their scenarios, but initiation mechanisms remain an open field to be investigated.

Klimkeit et al. [3] indeed assessed that previous propagation mechanisms are only related to the last $5 \%$ of the fatigue life. Prior to that, the fatigue damage is distributed in the structure, which is consistent with the continuum damage approach of Nouri et al. [8]. However, macroscopic measurements cannot capture initiation mechanisms. Numerical computations or specific experimental techniques at the microscopic scale are thus required for a better understanding. Klimkeit et al. [3] showed that fibre ends are indeed sites of stress concentrations and thus of debonding mechanisms, as already presented by Horst et al. [9]. They also identified the lateral interface of longitudinal fibres as critical site when neighbored fibres induce overstresses. On the contrary, Mourglia Seignobos [10] carried out observations at nano- and microscales and concluded that damage mechanisms are the same in neat and SGFR polyamide. From her point of view and for her material, they appear to be initiated in the matrix rather than at the fibre-matrix interface.

Determining fatigue mechanisms at the microscale is thus a current topic of research. Even if we can assume that fatigue damage is distributed in the sample and should probably be highly dependent on the local fibre orientation distribution and on the loading direction, no clear driving force is commonly reckoned 
in the literature to control the fatigue life for multiaxial loadings or various hygrothermal conditions, neither at the micro- nor at the macroscale.

\subsection{Fatigue}

\subsubsection{Parameters affecting the fatigue life}

Many parameters may have an influence on the fatigue life of SGFR thermoplastics. The following brief review highlights the different trends investigated in the literature.

Fibre orientation distribution (FOD) $[2,3,6,11]$. The influence of the microstructure has been investigated by working on different specimen geometries, thicknesses or locations with respect to the injection gate. The skin/core ratio is thus variable, as well as the fibre alignment degree in the tensile loading direction. The better the short fibre are oriented, the longer the fatigue life, but the slope of the $S$ - $N$ curves remains nearly constant.

Fibre length distribution (FLD) [12]. Micromechanical models based on the expression of the interfacial strength may explain the reduction of the tensile strength when decreasing the mean fibre length (or the aspect ratio), and may be extended to describe the same effect on the fatigue life. The slope of $S-N$ curves seems independent on the FLD.

Fibre volume content [13]. The fatigue life of stress-controlled specimens increases with the fibre content, as usually observed on static mechanical properties.

Multiaxial loading [2-4]. Tension and torsion loadings (in- and out-of-phase) are applied on thin tubular specimens. In the same way as for metallic materials, the shear stress seems to play an important role in the fatigue duration.

Mean-stress effects [13, 14]. When the mean stress is positive, creep-fatigue interactions are expected, which results in shorter fatigue life. Coupling between creep and fatigue has also been mentioned as a consequence of low frequencies by Horst and Spoormaker [5].

Loading direction with respect to material directions [11, 13, 15]. These studies are often performed on specimens milled out of injected plates at different angles. When the angle between the main fibre direction and the loading increases, the fatigue life decreases: the intercept of the $S$ - $N$ curves decreases, but the slope is nearly unaffected.

Water content $[6,16]$ and temperature $[4,7,10,11,17]$. The matrix behaviour becomes highly nonlinear when the temperature or the relative humidity increases [18]. The effects on the cyclic behaviour and fatigue life are similar, probably because higher water content in the matrix results in lower glass transition temperature. This material parameter controls the matrix ductility as well as the damage mechanisms with respect to environmental conditions. On the contrary, we restrain ourselves to conditions for which thermal ageing is negligible on fatigue duration, even if it may affect the static properties [19].

Frequency [13, 20-24]. Since thermoplastics poorly conduct heat, increasing the test frequency often re- 
sults in hysteretic heating. The specimen temperature is then higher than the ambient temperature, which may affect the fatigue life, as mentioned above. If the dissipated energy cannot be carried out by convection, the specimen temperature increases without stabilization and thermal fatigue occurs [25].

Notch effects [26]. As for metallic materials, notches induce local over-stresses on small volumes. A characteristic size of highly-stressed volume must be defined for the design of structural components. This is especially required if this volume is smaller than the representative volume of the microstructure.

\subsubsection{Available data in the literature}

In comparison with metallic materials, there used to be few available data in the literature for our specific material. However, some interesting papers have been recently published with fatigue life for different loading histories on samples made with polyamide 66 reinforced with $35 \mathrm{wt} \%$ of short glass fibres. Bernasconi et al. [12] provided fatigue life for ISO527-2-1A samples in repeated tension at room temperature in DAM and RH50 conditions. Sonsino and Moosbrugger [26] studied notch effects on injected tensile samples for two load ratios. Klimkeit [2] and De Monte et al. [4] have especially investigated multiaxial and mean-stress effects at room temperature on dry and conditioned tubular samples. Klimkeit [2] also published in his Ph.D fatigue data for tensile specimen milled out of injected plates. De Monte et al. [11] performed fatigue tests on tensile samples milled out of injected plates of different thicknesses at various angles, at room temperature and also at $130{ }^{\circ} \mathrm{C}$.

\subsubsection{Fatigue models for SGFR thermoplastics}

Among the previous works published in the literature regarding the fatigue of SGFR thermoplastics, many authors display their experimental data in $S-N$ curves, without suggesting a fatigue criterion. This may probably be explained by the fact that the fatigue behaviour of this kind of material has been investigated for much less time than metallic materials for example. For example, to the authors' knowledge, no fatigue criterion is able to describe the influence of all parameters mentioned in Sec. 1.3.1.

However, some recent papers give interesting clues regarding the directions to investigate for developing a new criterion. The influence of FOD, FLD, and loading direction on the fatigue life in tension may be described by a simple normalization of the $S$ - $N$ curves by the ultimate tensile strength $[11-13,15]$. The application of a modified Tsai-Hill criterion may be seen as an extension of this experimental fact, and leads to accurate fatigue life predictions $[11,15]$. However, such a criterion does not take into account mean-stress effects, neither has been applied to multiaxial loadings. Moreover, the coefficients are identified for one specific skin/core ratio: the application of the modified Tsai-Hill criterion is not easily suitable on industrial structures where both thickness and fibre alignment degree are variable.

Zago and Springer [27] proposed a fatigue criterion also based on the stress tensor, but explicitly taking 
into account the influence of the local orientation tensor. Their approach, also used by Gaier et al. [28], involves the determination of a critical plane for the fatigue of orthotropic materials; they assume that only the stress normal to the critical plane is responsible for fatigue damage. A structural application is presented in [28], but the authors do not validate their model on specimens for which local loadings and microstructures are well known. Without such work, their physical hypothesis needs further justification.

Klimkeit et al. [3] suggested that the density of elastic strain energy is well correlated to the fatigue life for multiaxial loadings. The criterion, inspired from the work of Kujawski and Ellyin [29], takes into account mean-stress effects. It has been successfully applied to other microstructures, such as tensile specimens milled out of injected plates. The authors eventually reckon that computations with an anisotropic elastic constitutive model may be improved by taking into account non-linear features in the matrix behaviour [2]. This remarks motivates the present work.

\subsection{Objective and structure of the paper}

The paper aims at suggesting a fatigue life model from data published in the literature on PA66-GF35. This criterion must take into account the influence of FOD and loading direction, as well as multiaxial and mean-stress effects. It should be noted that the influence of FLD and fibre volume content is not described because only one material is studied. Moreover, the test frequency is not especially investigated, but chosen in order to avoid hysteretic heating, and fatigue specimen are unnotched.

The outline of the paper is as follows. Section 2 presents the fatigue databases from the literature used in this work. In Section 3, constitutive equations for the cyclic behaviour of SGFR polyamides, developed in Part I of this work [1], are applied to the fatigue samples considered in this work; the existence of a steadystate regime is discussed. Several classical fatigue models are introduced in Section 4. The performance of these models, applied to fatigue test databases of the literature, are compared and discussed in Section 5. Final remarks and perspectives are given in Section 6 .

\section{Experimental data}

\subsection{Experimental conditions and samples}

In this paper, we analyze the fatigue data provided by De Monte et al. [4] as well as Klimkeit [2]. Both have studied the fatigue life of samples made of PA66-GF35 at room temperature. We here do not consider the work made by De Monte et al. [11,30] on samples milled out of injected plates since we currently perform a similar fatigue campaign. The comparison between both studies could be the topic of a future publication.

De Monte and coworkers studied injected tubular specimen in dry-as-molded (DAM) conditions (see Fig. 1a). The authors simulated the injection process with MoLdFLOW $\AA$, to determine the fibre orientation distribution in the sample. The fibre orientation in the center part of the tube appears homogeneous except 
in a small region induced by the injection gate location, and the short fibres are mostly oriented along the mould flow direction. However, a qualitative analysis of 3D X-ray computer tomography as well as quantitative analysis of $2 \mathrm{D}$ optical microscopy indicate that MoLDFLOw $\mathbb{R}$ overestimates the component $a_{11}^{\psi}$ of the second-order orientation tensor. Hence, the average of the orientation tensor over the thickness in the central part of the specimen is rather extrapolated from experimental data given by De Monte et al. $[4]^{1}$, and reads:

$$
\underline{\underline{a}}^{\psi}(\text { tube })=\left[\begin{array}{ccc}
0.76 & 0.00 & 0.00 \\
0.00 & 0.23 & 0.00 \\
0.00 & 0.00 & 0.01
\end{array}\right]_{\left(\underline{e}_{1}, \underline{e}_{2}, \underline{e}_{3}\right)}
$$

Klimkeit and co-workers studied the same tubular specimens, but in RH50 conditions. They added in their paper another kind of samples, i.e. dogbone tensile specimens milled out of injected plates at $0^{\circ}$ and $90^{\circ}$ (see Fig. 1b), which display a different microstructure. They also performed injection simulation to determine the fibre orientation in the plate, and thus in the center part of the dogbone specimen. Once again, the component of $\underline{a}^{\psi}$ along the moulding flow direction is overestimated. The coefficients of $\underline{a}^{\psi}$ are rather determined by a reverse identification, using the apparent tensile moduli at different angles, given in [3], and the elastic moduli of glass fibres and polyamide matrix, recalled in Tab. 2. This identification leads to the following estimation of the second-order orientation tensor in the middle of the plate:

$$
\underline{\underline{a}}^{\psi}(\text { plate })=\left[\begin{array}{ccc}
0.62 & 0.00 & 0.00 \\
0.00 & 0.28 & 0.00 \\
0.00 & 0.00 & 0.10
\end{array}\right]_{\left(\underline{e}_{1}, \underline{e}_{2}, \underline{e}_{3}\right)}
$$

\subsection{Mechanical loadings}

The two studies performed by De Monte et al. or Klimkeit et al. display a wide range of loading cases. Tubular specimens (see Fig. 1a) are subjected to pure tension, pure torsion or combined tension and torsion. Combined loading may be either in-phase $\left(\delta=0^{\circ}\right)$ or out-of-phase $\left(\delta=90^{\circ}\right)$, with different biaxiality ratios. Following [4], we define the biaxility ratio $\lambda_{2} \equiv \tau_{12} / \sigma_{11}$, with $\tau_{12}$ the shear stress in the center part of the tubular specimen, and $\sigma_{11}$ the axial stress. $\lambda_{2}$ equals 0 in case of pure tension; $1 / 3,1 / 2$ or 1 in case of combined tension-traction; $\infty$ in case of pure torsion. Moreover, due to the geometry of the tubular specimen, a tensile axial loading induces a circumferential stress $\sigma_{22}$. De Monte et al. evaluated this second biaxiality ratio as $\lambda_{1} \equiv \sigma_{22} / \sigma_{11}=0.22$.

\footnotetext{
${ }^{1}$ The axisymmetry of the problem explains why $\underline{a}^{\psi}$ is supposed to be diagonal in axes $\left(\underline{e}_{1}, \underline{e}_{2}, \underline{e}_{3}\right)$. $a_{11}^{\psi}$ is a mean value over the cross section of the tubular sample measured by optical microscopy [4], whereas $a_{33}^{\psi}$ is arbitrarily assigned to 0.01 since Klimkeit et al. [3] note that only very few fibres are out-of-plane. Eventually, the condition $\operatorname{Tr}\left(\underline{\underline{a}}^{\psi}\right)=1$ leads to $a_{22}^{\psi}$.
} 


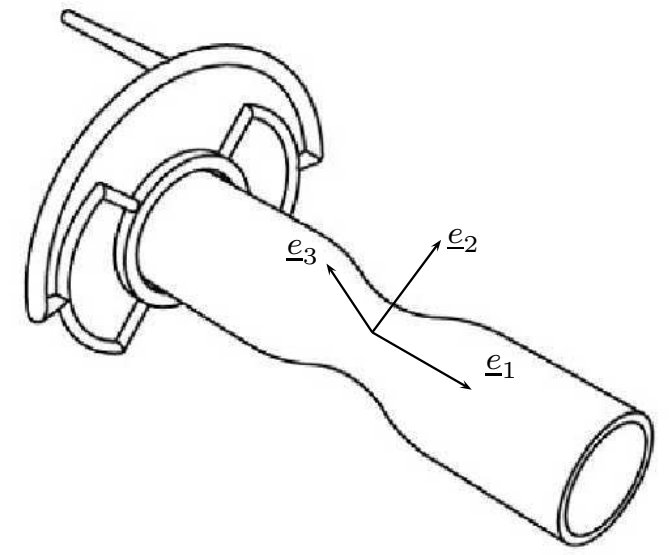

(a) Injected tubular specimen, from [2]. $\underline{e}_{1}$ is the revolution axis, $\underline{e}_{2}$ the orthoradial axis, and $\underline{e}_{3}$ the out-of-plane (radial) axis.

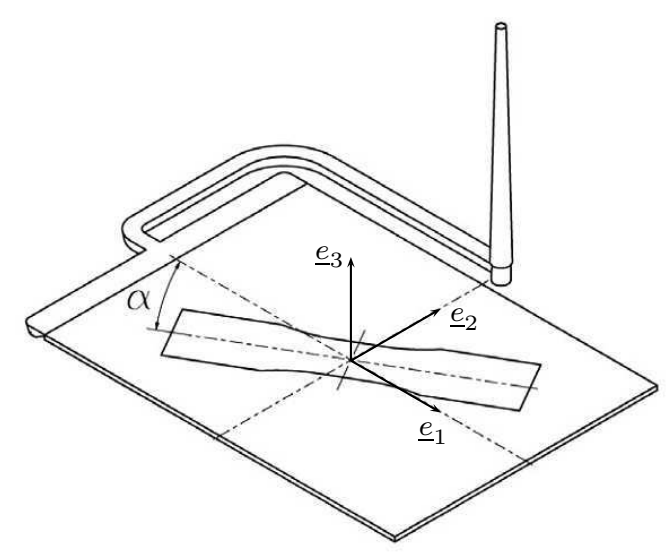

(b) Dogbone specimen milled out of injected plates, from [2]. $\underline{e}_{1}$ is the moulding flow axis, $\underline{e}_{2}$ the inplane perpendicular axis, and $\underline{e}_{3}$ the out-of-plane axis.

Figure 1: Geometry of fatigue specimen studied in this paper. See the given references for details on specimen dimensions.

In the case of nonlinear behaviour, the stress tensor should be computed in the center part of the specimen through an appropriate FE simulation taking into account the influence of the FOD as well as the nonlinear strain mechanisms [31]. Unfortunately, injection parameters or rheological properties of the material are not specified, which means that an accurate (nonlinear) relationship between the applied load and torque and the local stress components remains unknown. However, the cross section of the central part of tubular samples is smaller, and must therefore concentrate strains and stresses. For that reason, no major stress redistribution due to residual viscoplastic strains is expected. Since the tests are load-controlled, we assume that the local stress histories computed by De Monte through linear elastic simulation are correct. In the following of this work, values of constant (elastic) parameters $\lambda_{1}$ and $\lambda_{2}$ are kept as given in [4].

The dogbone specimens studied by Klimkeit et al. (see Fig. 1b) are only subjected to pure tension. These samples are interesting in order to perform tests on a different microstructure, the loading axis being parallel $\left(\lambda_{1}=0\right)$ or perpendicular $\left(\lambda_{1}=\infty\right)$ to the main fibre alignment direction, $\underline{e}_{1}$.

The loading signals are sinusoidal. The load ratio $R \equiv \sigma_{\min } / \sigma_{\max }$ equals 0 (tension-tension or torsiontorsion) or -1 (fully-reversed loading) ${ }^{2}$. Different stress levels are performed for each loading case. The frequency is not specified by the authors, but is chosen in order to moderate the hysteretic heating of the specimens. We assume that the frequency range is between 1 and $5 \mathrm{~Hz}$, the higher frequencies being applied at lower stress levels.

\footnotetext{
${ }^{2}$ In the case of the dogbones samples studied by Klimkeit and co-workers, $R$ is 0.1 rather than 0.
} 


\begin{tabular}{|c|c|c|c|c|c|c|c|c|c|c|}
\hline \multirow{2}{*}{\multicolumn{2}{|c|}{$\frac{\text { Specimen }}{\text { Short denomination }}$}} & \multicolumn{7}{|c|}{ Tubular } & \multicolumn{2}{|c|}{ Dogbone } \\
\hline & & \multirow{4}{*}{$\begin{array}{c}\operatorname{Tr} \\
0.22 \\
0\end{array}$} & \multirow{4}{*}{$\begin{array}{l}\text { To } \\
\infty\end{array}$} & \multirow{4}{*}{$\begin{array}{c}\text { Tr } \propto \text { To } \\
0.22 \\
1 \\
0^{\circ} \\
\end{array}$} & \multirow{4}{*}{$\begin{array}{c}\text { Tr } \not \text { To } \\
0.22 \\
1 \\
90^{\circ} \\
\end{array}$} & \multirow{4}{*}{$\begin{array}{c}2 \mathrm{Tr} \propto \mathrm{To} \\
0.22 \\
1 / 2 \\
0^{\circ} \\
\end{array}$} & \multirow{4}{*}{$\begin{array}{c}3 \mathrm{Tr} \propto \mathrm{To} \\
0.22 \\
1 / 3 \\
0^{\circ} \\
\end{array}$} & \multirow{4}{*}{$\begin{array}{c}3 \operatorname{Tr} \propto \text { To } \\
0.22 \\
1 / 3 \\
90^{\circ}\end{array}$} & \multirow{4}{*}{$\begin{array}{c}\operatorname{Tr} \| \\
0 \\
0\end{array}$} & \multirow{4}{*}{$\begin{array}{c}\operatorname{Tr} \perp \\
\infty \\
0\end{array}$} \\
\hline & $\lambda_{1}$ & & & & & & & & & \\
\hline Parameters & $\lambda_{2}$ & & & & & & & & & \\
\hline & $\delta$ & & & & & & & & & \\
\hline \multirow{2}{*}{$\begin{array}{c}\text { De Monte } \\
\text { DAM, } 23^{\circ} \mathrm{C} \\
\end{array}$} & $R=0$ & - & $\bullet$ & $\triangleright$ & 4 & & $\Delta$ & $\nabla$ & & \\
\hline & $R=-1$ & $\square$ & 0 & $\triangleright$ & $\triangleleft$ & & $\Delta$ & $\nabla$ & & \\
\hline \multirow{2}{*}{$\begin{array}{c}\text { Klimkeit } \\
\text { RH50, } 23^{\circ} \mathrm{C} \\
\end{array}$} & $R=0$ & - & $\bullet$ & & & $\Delta$ & & & $\square$ & $\square$ \\
\hline & $R=-1$ & $\square$ & 0 & & & $\Delta$ & & & $\square$ & $\square$ \\
\hline
\end{tabular}

Table 1: Sum up of the different loading cases tested by De Monte et al. [4] as well as Klimkeit [2], Klimkeit et al. [3], along with the symbols used in this paper: "Tr" means pure tension, "To" means pure torsion, " $n \operatorname{Tr} \propto \operatorname{To"~(resp.~"~} n \operatorname{Tr} \propto T 0 ")$ means in- (resp. out-of-) phase tension-torsion with biaxility ratio $\lambda_{2}=1 / n$, "Tr|\|" (resp. "Tr $\perp ")$ means pure tension on dogbone specimen milled out of plate along (resp. perpendicular to) the molding flow direction.

To sum up, the two studies represent a very rich database (see Tab. 1), which takes into account the influence of environmental conditions (DAM or RH50), amount of shear stress $\left(\lambda_{2}=0,1 / 3,1 / 2,1, \infty\right)$, mean stress effects $(R=0,-1)$, and non-proportionality of the loading $\left(\delta=0,90^{\circ}\right)$. Two microstructures are tested (tubular or dogbone specimens), and the loading direction may be parallel or perpendicular to the main fibre alignment $\left(\lambda_{1}=0,0.22, \infty\right)$.

Only plane stress cases are studied, but they are representative of most stress states observed on industrial components of the air-intake circuit.

\subsection{Measurements}

In the following of this paper, fatigue life is characterized by the number of cycles at which the specimen is entirely broken. As shown by Klimkeit et al. [3], as well as Noda et al. [7], the failure of the whole sample occurs very fast after the detection of a crack initiation. This crack initiation may be detected by a stiffness loss, a temperature rise, a damping parameter variation or even by experimental observations (replica technique, SEM). This is the reason why we neglect the propagation step of the macro-crack, and even if the fatigue criterion should be stricto sensu a criterion for initiation, only the number of cycles to failure $N_{r}$ is considered.

As reported by Klimkeit et al. [32], the failure often occurs in the central part of tubular specimens, or sometimes in the parallel length of dogbone specimens. De Monte et al. [4] reported that the main crack always appears in the central part of the specimen, except in a few cases (especially under pure tension). 


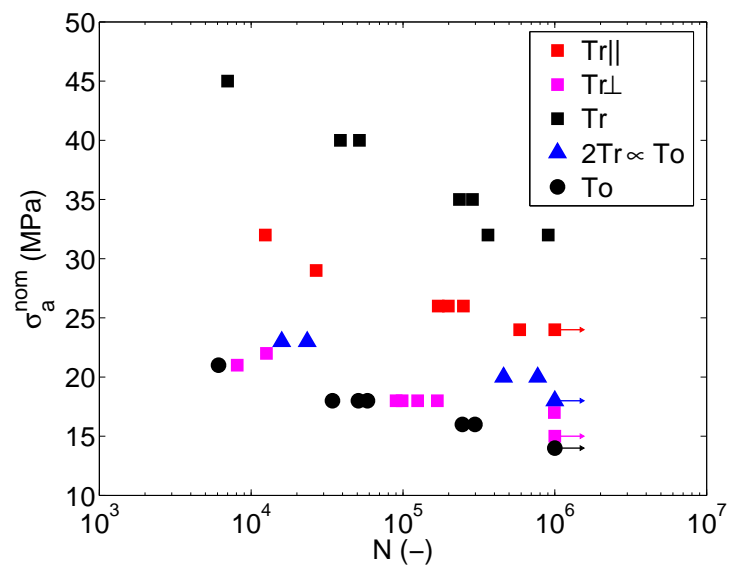

(a) $R=0$

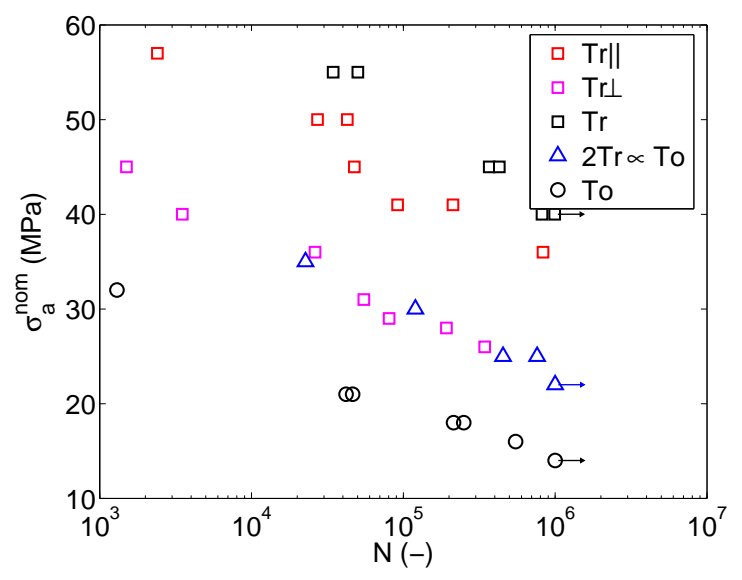

(b) $R=-1$

Figure 2: Fatigue database on conditioned material $\left(\mathrm{RH} 50,23^{\circ} \mathrm{C}\right)$, from [2], for two load ratios. The vertical axis stands for the amplitude of the nominal applied stress. It equals $\sigma_{11}$ for pure tensions cases $\operatorname{Tr} \|$ and $\operatorname{Tr}$, and $\sigma_{22}$ for $\operatorname{Tr} \perp$. In the case of combined tension-torsion $2 \operatorname{Tr} \propto \operatorname{To}, \tau_{12}=\lambda_{2} \sigma_{11}$ is applied additionally; $\tau_{12}$ is plotted instead of $\sigma_{11}$ in the case of pure torsion To. $\sigma_{22}=\lambda_{1} \sigma_{11}$ is also applied for tubular specimens.

Without further information, we do not consider these cases, and in this paper, the critical area (i.e. the area where a crack nucleates) of the tubular specimen will always be its central part.

In accordance with previous studies published in the literature about the fatigue life of SGFR thermoplastics, the fatigue scattering is small, especially in comparison with the fatigue of metallic materials. This point is illustrated in Fig. 2, in which the experimental data of Klimkeit et al. are gathered. In every other graphic of this paper, to limit the number of points, only the logarithmic mean of the number of cycles to failure will be plotted for each loading case, when several tests are made in the same conditions.

\section{Computation of the local cyclic response}

\subsection{Application of the nonlinear constitutive behaviour}

In this paper, the constitutive behaviour for SGFR polyamide proposed in the first part of this work [1] is applied to compute the local mechanical response under a given stress tensor. The model parameters have been identified and validated in DAM and RH50 conditions at room temperature $[1,33]$ on tensile samples. This model has not been validated on multiaxial samples, but its application to structural samples (where local stresses are multiaxial) leads to accurate correlations between experimental and computed mechanical responses [31].

Even if the grade of PA66-GF35 used by De Monte et al. [4], Klimkeit [2] and ourselves is not the same, we assume that in the same environmental conditions, two different grades of PA66-GF35 have nearly the same 


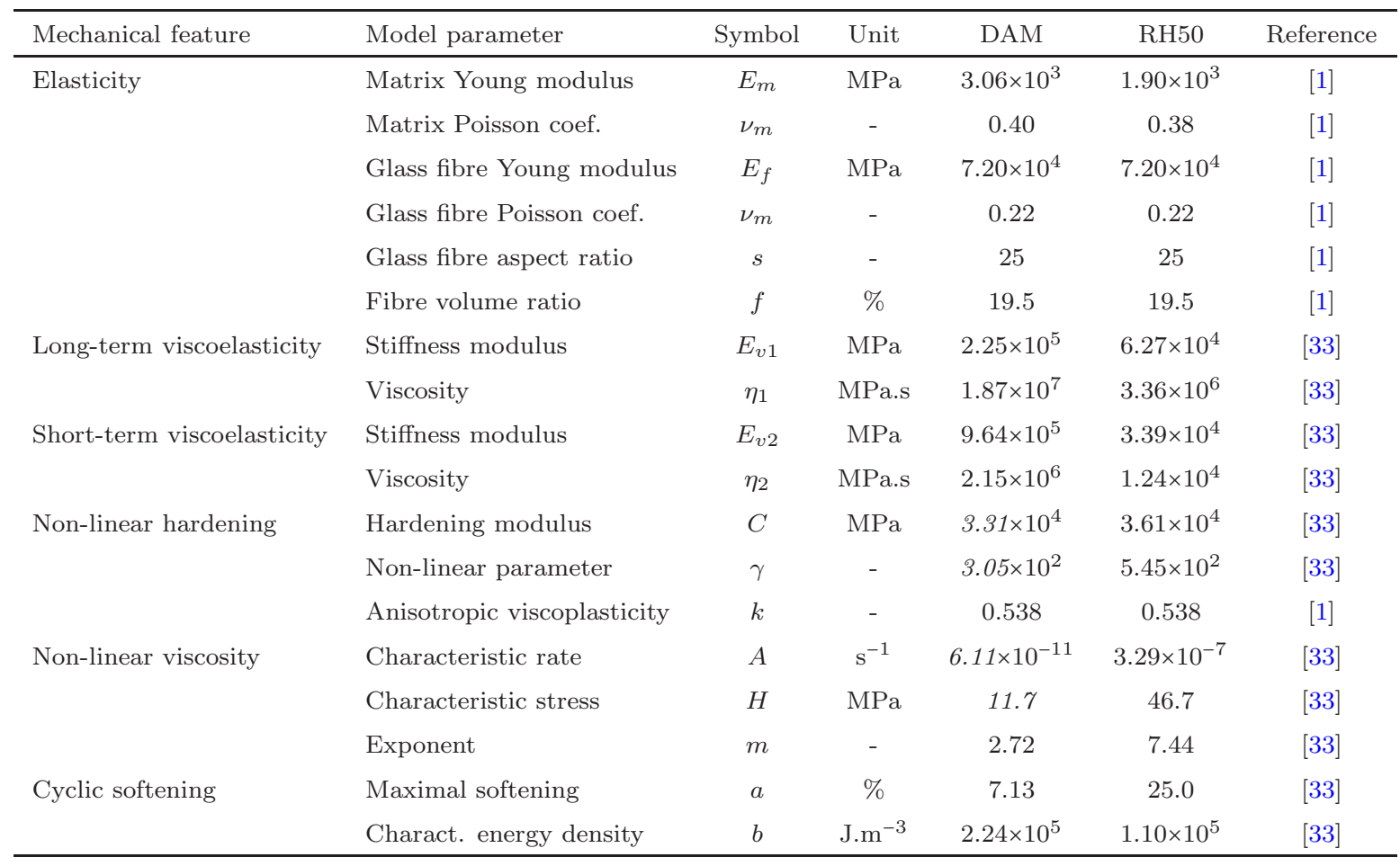

Table 2: Coefficients involved in the proposed constitutive model. The numerical values are given for the dry-as-molded (DAM) and for the conditioned (RH50) material at room temperature. Numbers in italic letters have been modified in comparison with values originally proposed in [33], to fit De Monte et al. [30]'s data in monotonic tensions.

mechanical response. Not much experimental data is available in the literature to validate this hypothesis, since only elastic properties are usually regarded in other publications about SGFR thermoplastics. However, De Monte et al. [30] and Klimkeit [2] published a few experimental tensile curves, as well as quantitative information regarding local orientation tensors. Fig. 3 presents the comparison between model predictions and experimental data with model parameters gathered in Tab. 2. The correlation on conditioned material is good, since the mechanical response at high stress levels (above $90 \mathrm{MPa}$ ) do not regard fatigue applications. Original material parameters for DAM material lead to an overestimation of the tangent stiffness above 50 $\mathrm{MPa}$, which is the reason why viscoplastic parameters have been slightly modified to match experimental data. This small correction may be imputed to the different material grade, or to a limited water uptake from the DAM condition to approximatively RH5. In the following of this study, we consider that the proposed constitutive model leads to an accurate mechanical response, regarding both anisotropy and non-linearity of the material behaviour, in both DAM and RH50 conditions (at room temperature). 


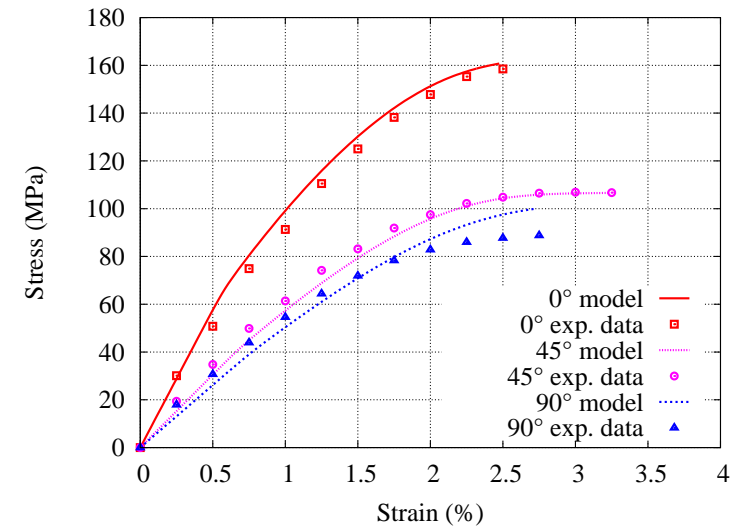

(a) DAM material

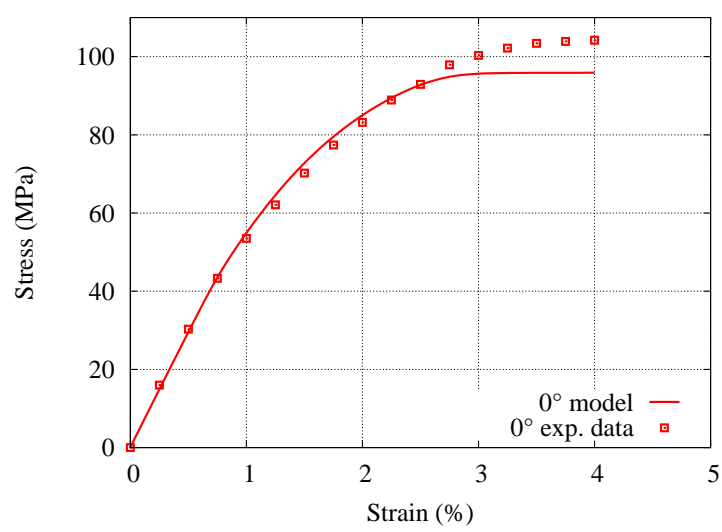

(b) RH50 material

Figure 3: Application of the constitutive model to strain-controlled static tests on PA66-GF35 from the literature: (a) tensile samples milled out of plates at various angles (DAM, $23^{\circ} \mathrm{C}$, thickness $1 \mathrm{~mm}$ ) [30]; (b) tensile sample milled out of plate in the mould flow direction (RH50, $23^{\circ} \mathrm{C}$, thickness $3 \mathrm{~mm}$ ) [2].

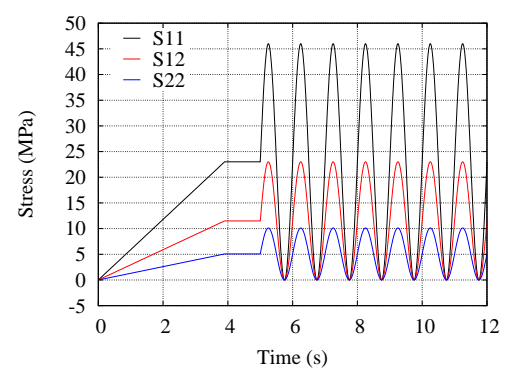

(a) Stress history

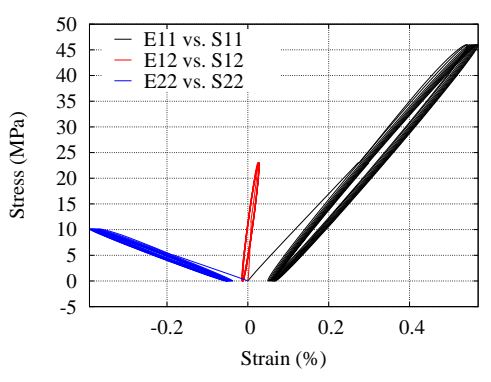

(b) Strain-stress response

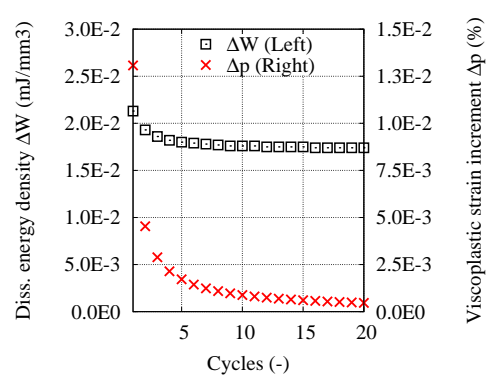

(c) Cyclic evolution

Figure 4: Example of a stress history applied to a representative volume in the central part of the tubular specimen $\left(23^{\circ} \mathrm{C}, \mathrm{RH} 50\right)$, and mechanical response of the proposed model over 20 cycles. Here, the load ratio $R$ equals 0 , tension and torsion signals are in phase, at a frequency of $1 \mathrm{~Hz}$, and biaxility ratios are $\lambda_{1}=0.22$ and $\lambda_{2}=0.5 . \Delta p=\int_{\text {cycle }} \dot{p} \mathrm{~d} t$ stands for the increment of viscoplastic cumulated strain and $\Delta W_{\text {diss }}$ for the dissipated energy density over one cycle (see Part I [1]). 


\subsection{Simulation of the cyclic response under multiaxial fatigue loading}

We now consider fatigue loadings studied by Klimkeit et al. $\left(23^{\circ} \mathrm{C}, \mathrm{RH} 50\right)$ and De Monte et al. $\left(23^{\circ} \mathrm{C}\right.$, DAM). As above-mentioned, we do not compute the whole specimen, but only a representative volume in the central part of the tubular as well as dogbones specimens. The fibre orientation has already been characterized for both microstructures (see Sec. 2.1). The mechanical loading is multiaxial, and may be symbolized by a local stress history as:

$$
\underline{\underline{\sigma}}(t)=\left[\begin{array}{ccc}
\sigma_{11}^{m}+\sigma_{11}^{a} \times \sin (2 \pi f t) & \tau_{12}^{m}+\tau_{12}^{a} \times \sin (2 \pi f t+\delta) & 0 \\
\tau_{12}^{m}+\tau_{12}^{a} \times \sin (2 \pi f t+\delta) & \sigma_{22}^{m}+\sigma_{22}^{a} \times \sin (2 \pi f t) & 0 \\
0 & 0 & 0
\end{array}\right]
$$

where the superscripts $m$ and $a$ respectively denote the mean and amplitude of each stress component. $f$ is the loading frequency and $\delta$ the phase angle between tension and torsion (i.e. between local tension and shear).

Figure 4 displays the result of such a simulation under combined tension-torsion loading, over 20 cycles. One can see that the predicted mechanical response converges toward a stationary state in terms of strain amplitude, dissipated energy density or viscoplastic strain increment. In part I of this work, 20 cycles are shown to be sufficient for capturing the steady-state of the experimental cyclic response.

\subsection{Steady-state of the simulated cyclic response}

It is well known that an elastoviscoplastic structure subjected to cyclic loading may present three different asymptotic (long-term or steady-state) regimes, namely: elastic shakedown (including perfect elasticity), plastic shakedown and ratcheting. In our case, the behaviour is rather viscoelastic-viscoplastic, and the elastic shakedown may be generalized to viscoelastic shakedown. To identify these different steady-states and to capture the trend line of the multiaxial evolution of internal variables, a numerical procedure has been proposed by Benoit et al. [34]. In the case of ratcheting, characterized by the absence of stabilization of the inelastic strain (which may be the consequence of creep-fatigue coupling), a ratcheting part and a cyclic part can be extracted from each cycle. A constant cyclic part means that a steady state is reached.

Practically, the simplified procedure proposed by Benoit et al. [34] is used here to check whether a steady-state is reached. The mean viscoplastic strain (i.e. the ratcheting or creep strain) ${\underline{\varepsilon^{\star}}}^{\star}$ is obtained by:

$$
\underline{\underline{\varepsilon}}^{\star}(t)=\arg \min _{\underline{\underline{\varepsilon^{1}}}} \max _{t \in I_{t}}\left\|\underline{\underline{\varepsilon}}^{1}-\underline{\underline{\varepsilon}}_{v p}(t)\right\|_{e}
$$

where $I_{t}$ is a time-period interval and $\|\cdot\|_{e}$ stands for the following tensorial norm $\|\underline{\underline{t}}\|_{e}=\sqrt{\frac{2}{3} \underline{\underline{t}}: \underline{\underline{t}}}$. The cyclic viscoplastic strain is defined as:

$$
\underline{\underline{\varepsilon}}^{c}(t)=\underline{\underline{\varepsilon}}_{v p}(t)-\underline{\underline{\varepsilon}}^{*}(t)
$$




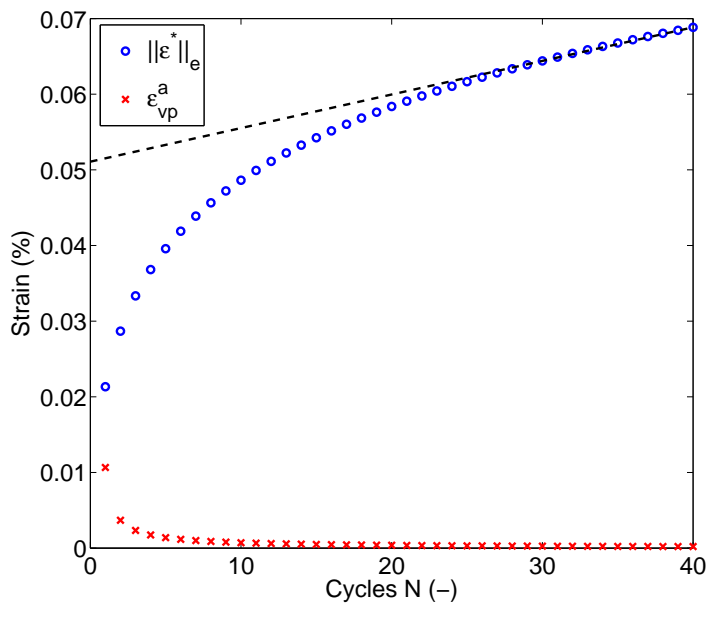

(a) $2 \operatorname{Tr} \propto \operatorname{To:} R=0, \sigma_{11}^{a}=23 \mathrm{MPa}$

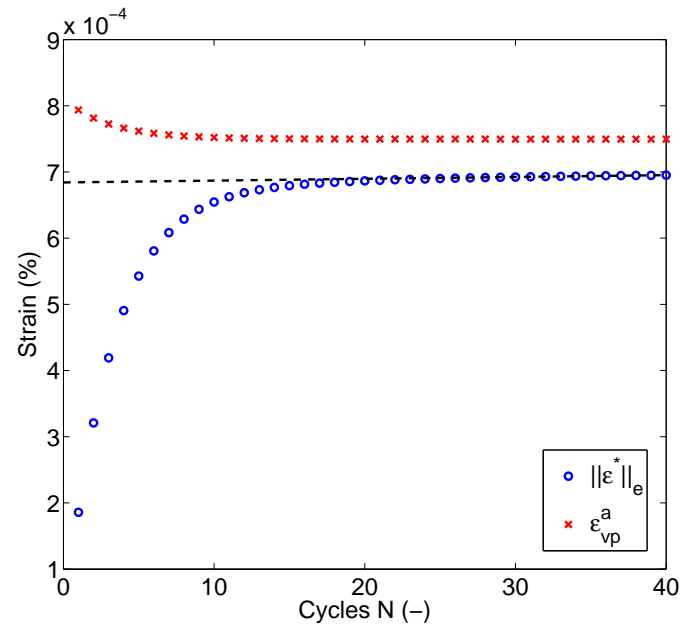

(b) $\operatorname{Tr}: R=-1, \sigma_{11}^{a}=55 \mathrm{MPa}$

Figure 5: Evolution of the mean strain norm $\left\|\underline{\underline{\varepsilon}}^{*}\right\|_{e}$ and of the cyclic viscoplastic strain amplitude $\varepsilon_{a}^{v p}$ over 40 cycles, for conditioned tubular specimens subjected to two different loading histories: (a) combined tensiontorsion, (b) tension-compression. The dotted line indicates the asymptotic regime of the mean strain.

Finally, the cyclic viscoplastic amplitude $\varepsilon_{v p}^{a}(t)$ reads:

$$
\varepsilon_{v p}^{a}(t)=\min _{\underline{\underline{\varepsilon}}^{1}} \max _{t \in I_{t}}\left\|\underline{\underline{\varepsilon}}^{1}-\underline{\underline{\varepsilon}}_{v p}(t)\right\|_{e}=\max _{t \in I_{t}}\left\|\underline{\underline{\varepsilon}}^{c}(t)\right\|_{e}
$$

Figure 5 displays the application of this procedure to two different examples of multiaxial fatigue loadings. It shows that the cyclic viscoplastic strain amplitude stabilizes for 20 cycles, while the mean strain norm evolves linearly with $N$, which means that the ratcheting rate is constant. In the following of this paper, we therefore consider that 20 cycles are sufficient to reach the steady-state and we assume that mechanical quantities computed on the 20th cycle are representative of the mechanical state of the material during its fatigue life. Such an hypothesis is required for any approach uncoupling cyclic behaviour and fatigue damage, but it is justified both from experimental point of view [see Part I of this work, 1] and numerical point of view.

\section{Fatigue models}

\subsection{Objective}

The objective of the section is to seek for a phenomenological macroscopic approach of fatigue lifetime for SGFR structures. Such a model could be inspired from the huge experience on metallic materials. In the literature on metallic materials, fatigue domains are classified according to the characterisitics of the 
stabilized cycle [35-38]. If there is no stabilized cycle, for example in the case of continuous ratcheting, the fatigue life is usually very short, and we consider that a methodology like continuum damage mechanics is more relevant.

The cases where the stabilized cycle is dissipative at the macroscopic scale - a phenomenon known as plastic shakedown - represent the low cycle fatigue (LCF) domain. The lifetime is expected between a few hundreds to thousands of cycles. At the opposite, the high cycle fatigue (HCF) regime is related to a non-dissipative stabilized cycle at the macroscopic scale. The hysteretic area is negligible, and one speaks about elastic shakedown. The lifetime is usually from tens of thousands to millions of cycles, or may even be assumed as infinite.

In the works of Klimkeit [2] and De Monte et al. [4], the fatigue life is from thousands to millions of cycles. No endurance limit is observed. Because of short-term viscoelastic effects, even low stress loadings result in a macroscopic hysteresis $[1,11,32]$. For this reason, both LCF and HCF fatigue models can be used to guide the development of new models suitable for SGFR and are discussed in this paper. The purpose is not to present an exhaustive review of fatigue criteria, but rather to check the relevancy and to compare the accuracy of some classical approaches for predicting the fatigue life under multiaxial loadings of SGFR polyamide.

\subsection{Methodology}

Several existing or proposed fatigue lifetime models are examined, and their ability to accurately predict the fatigue life on the De Monte's and Klimkeit's database is evaluated. The criteria, detailed in the next subsections, are based on von Mises stress, Hill stress, equivalent shear stress and hydrostatic stress (Sines, Crossland and Dang Van), modified Tsai-Hill criterion, principal stress, principal strain, equivalent inelastic strain or dissipated energy density. Formally, they can be written as:

$$
\log N_{r}=f\left(G_{i}, i=1, n_{c} ; p_{k}, k=1, n_{p}\right)
$$

$N_{r}$ is the number of cycles to failure, $G_{i}\left(i \in\left[1, \ldots n_{c}\right]\right)$ are $n_{c}$ physical quantities involved in the criterion (for instance, the shear stress amplitude, the hydrostatic stress, the viscoplastic strain amplitude...); $p_{k}$ $\left(k \in\left[1, \ldots n_{p}\right]\right)$ are the $n_{p}$ material parameters of the criterion.

For each test of the database, the mechanical response is computed over 20 cycles (see Sec. 3.3), and the physical quantities $G_{i}$ are post-processed on the 20 th cycle. The material parameters $p_{k}$ are then calibrated using the least square method on the whole tests database; and therefore the optimal parameters (i.e. the value which minimizes the scatter between the tests) for the criterion are obtained. At last, the different physical quantities $G_{i}$ (or their combinations) are plotted against the number of cycles to failure $N_{r}$ in a $\log$-log diagram $\left(\log G_{i}\right.$ versus $\left.\log N_{r}\right)$. The residual error of the least square method is also displayed as err $=\sqrt{\frac{\sum_{i=1}^{n}\left(\log N_{r}^{\exp , i}-\log N_{r}^{\operatorname{sim}, i}\right)^{2}}{n}}$, where $n$ is the number of tests in the fatigue database. err is an estimation 


\begin{tabular}{lll}
\hline Criterion & DAM, $23^{\circ} \mathrm{C}$ & RH50, $23^{\circ} \mathrm{C}$ \\
\hline Shear-stress (von Mises) & $b=9.16 \mathrm{MPa}, \sigma_{0}=78.1 \mathrm{MPa}$ & $b=10.3 \mathrm{MPa}, \sigma_{0}=70.3 \mathrm{MPa}$ \\
Shear-stress (Hill) & $b=17.4 \mathrm{MPa}, \sigma_{0}=148 \mathrm{MPa}$ & $b=16.7 \mathrm{MPa}, \sigma_{0}=120 \mathrm{MPa}$ \\
Crossland & $\alpha=0.440, b=16.3 \mathrm{MPa}, \sigma_{0}=152 \mathrm{MPa}$ & $\alpha=0.392, b=16.3 \mathrm{MPa}, \sigma_{0}=124 \mathrm{MPa}$ \\
Sines & $\alpha=1.04, b=13.2 \mathrm{MPa}, \sigma_{0}=133 \mathrm{MPa}$ & $\alpha=0.970, b=12.7 \mathrm{MPa}, \sigma_{0}=104 \mathrm{MPa}$ \\
Dang Van & $\alpha=0.118, b=8.94 \mathrm{MPa}, \sigma_{0}=78.0 \mathrm{MPa}$ & $\alpha=0.153, b=10.4 \mathrm{MPa}, \sigma_{0}=71.3 \mathrm{MPa}$ \\
Mod. Tsai-Hill & $\sigma_{\text {longi }}=155 \mathrm{MPa}, \sigma_{\text {transv }}=24.5 \mathrm{MPa}, \quad$ & $\sigma_{\text {longi }}=118 \mathrm{MPa}, \sigma_{\mathrm{transv}}=13.2 \mathrm{MPa}$, \\
& $\tau_{\text {longi }}=45.0 \mathrm{MPa}, b=8.02$ & $\tau_{\text {longi }}=24.3 \mathrm{MPa}, b=5.13$ \\
Principal stress & $b=31.4 \mathrm{MPa}, \sigma_{0}=210 \mathrm{MPa}$ & $b=27.5 \mathrm{MPa}, \sigma_{0}=168 \mathrm{MPa}$ \\
Principal strain & $b=2.22 \mathrm{e}-3, \varepsilon_{0}=1.75 \mathrm{e}-2$ & $b=3.32 \mathrm{e}-3, \varepsilon_{0}=2.24 \mathrm{e}-2$ \\
Manson-Coffin & $b=1.39, C=30.3$ & $b=1.61, C=192$ \\
Energy & $b=0.693, C=3.84 \mathrm{~mJ} / \mathrm{mm}^{3}$ & $b=0.652, C=26.8 \mathrm{~mJ} / \mathrm{mm}^{3}$ \\
Amiable & $\alpha=-2.12 \mathrm{e}-6, b=0.738, C=5.86 \mathrm{~mJ} / \mathrm{mm}^{3}$ & $\alpha=1.36 \mathrm{e}-4, b=0.568, C=12.0 \mathrm{~mJ} / \mathrm{mm}^{3}$ \\
Modified Energy & $\alpha=52.6, b=0.401, C=2.95 \mathrm{~mJ} / \mathrm{mm}^{3}$ & $\alpha=0.120, b=0.701, C=6.99 \mathrm{~mJ} / \mathrm{mm}^{3}$ \\
\hline
\end{tabular}

Table 3: Parameters of the tested HCF and LCF criteria for both environmental conditions. Note that some values have no physical meaning since the criteria may not be relevant.

of the standard deviation around the fatigue prediction: the smaller it is, the more accurate the criterion is. Tab. 3 sums up the different tested criteria, with the values of the optimal parameters.

Let us recall that the calibration of the fatigue models parameters is made over whole Klimkeit's or De Monte's databases. Contrary to others publications [e.g. 32], this work does not aim at identifying a fatigue model from a few loading conditions, and at validating it on other loading conditions. It rather aims at looking for physical quantities $G_{i}$ which show the best correlation with the fatigue life for various loading cases. Hence, no specific identification strategy is considered in this work, since it may induce a bias when comparing the correlations given by the different physical quantities.

\subsection{Stress based fatigue models}

\subsubsection{Shear-stress criteria}

We consider a shear-stress based fatigue model formulated as:

$$
\log N_{r}=\frac{\sigma_{0}-J_{2}^{a}(\underline{\underline{\sigma}})}{b}
$$

$\sigma_{0}$ and $b$ are criterion parameters. $J_{2}(\underline{\underline{\sigma}})$ is a scalar measuring the octahedral shear-stress intensity according to either the von Mises norm or the anisotropic Hill norm. Its amplitude is defined as the radius of the smallest hypersphere circumscribing the loading path in the 5-dimension deviatoric stress space [39]:

$$
J_{2, \text { vonMises }}^{a}(\underline{\underline{\sigma}})=\min _{\underline{\underline{s}}} \max _{t \in\left[0, T_{\text {cycle }}\right]}\left[\sqrt{\frac{3}{2}\left(\underline{s}_{1}-\underline{\underline{s}}(t)\right):\left(\underline{\underline{s}}_{1}-\underline{\underline{s}}(t)\right)}\right]
$$


with the von Mises norm, or in the case of the Hill norm (which is also pressure-insensitive):

$$
J_{2, \text { Hill }}^{a}(\underline{\underline{\sigma}})=\min _{\underline{\underline{s}}_{1}} \max _{t \in\left[0, T_{\text {cycle }}\right]}\left[\sqrt{\left(\underline{\underline{s}}_{1}-\underline{\underline{s}}(t)\right): \mathbb{P}:\left(\underline{\underline{s}}_{1}-\underline{\underline{s}}(t)\right)}\right]
$$

The shear-stress criterion based on the von Mises norm has been already tested by Klimkeit [2], Klimkeit et al. [3].

\subsubsection{Criteria based on shear stress and hydrostatic stress}

These criteria have been initially formulated to estimate endurance limit under multiaxial loadings. Their formulation stems from the observation that the hydrostatic stress has an effect on the fatigue life, and especially on the endurance limit. They may be generalized to estimate not only the fatigue limit, but also the number of cycles to failure [40,41]. The fatigue lifetime model inspired from the Crossland criterion (hereinafter called, for brevity, Crossland criterion) is written as:

$$
\log N_{r}=\frac{\sigma_{0}-\left(J_{2}^{a}(\underline{\underline{\sigma}})+\alpha P_{\max }\right)}{b}
$$

$P_{\max }$ is the maximum of the hydrostatic stress over the stabilized cycle. The Sines inspired criterion is slightly different, as it does not involve the maximum but the mean value of the hydrostatic stress:

$$
\log N_{r}=\frac{\sigma_{0}-\left(J_{2}^{a}(\underline{\underline{\sigma}})+\alpha P_{\mathrm{avg}}\right)}{b}
$$

The Dang Van criterion explicitly searches for the material orientation $\underline{n}$ which is subjected to the highest shear $\tau$ and maximal hydrostatic stress combination. The Dang Van inspired fatigue lifetime model is written as:

$$
\log N_{r}=\frac{\sigma_{0}-\max _{\underline{n}} \max _{t}\left[\tau(\underline{n}, t)+\alpha P_{\max }(t)\right]}{b}
$$

All these criteria are based on the same physical ideas, but do not lead to the same correlation with $N_{r}$ on fatigue databases involving various loading cases. Let us recall that, as mentioned in Sec. 4.2, parameters $\alpha$ and $b$ are calibrated to minimize the scattering.

\subsubsection{Proposition of a model based on Tsai-Hill criterion (Modified Tsai-Hill criterion)}

We have stated (see Sec. 1.3) that the formulation of the modified Tsai-Hill criterion used in $[11,15]$ is not easily applicable to industrial structures made out of SGFR thermoplastics. This is the reason why a new version of the modified Tsai-Hill criterion, explicitly taking into account the FOD (through the orientation tensor $\underline{a}^{\psi}$ ), is proposed. Details are given in Annexe A.

The stress tensor is expressed in material axes: $\underline{\underline{\sigma}}=\bar{\sigma}_{i j} \underline{u}_{i} \otimes \underline{u}_{j}$, with $i \in[1,2,3]$. We distinguish the stress components $\bar{\sigma}_{i i}$ along the main fibre direction $\underline{u}_{i}$, the transverse stresses $\bar{\sigma}_{j j}(j \neq i)$ relative to the direction $\underline{u}_{i}$, and the shear stresses relative to this direction, $\bar{\sigma}_{i j}(j \neq i)$. All these components are weighted 
by the fibre alignment intensity along each of these directions, $a_{i}$, and the proposed modified Tsai-Hill criterion reads:

$$
G_{\mathrm{T}-\mathrm{H}}\left(\underline{\underline{\sigma}}, \underline{\underline{a}}^{\psi}\right)=\sqrt{\underline{\underline{\sigma}}: \mathbb{M}\left(\underline{\underline{a}}^{\psi}\right): \underline{\underline{\sigma}}}
$$

$\mathbb{M}$ is a fourth-order tensor, in accordance with Hill's theory [42]. It is supposed to be orthotropic in material axes. Its coefficients depend on the orientation intensity $a_{i}$, and involve three material parameters. $\mathbb{M}$ is written as:

$$
\mathbb{M}\left(\underline{\underline{a}}^{\psi}\right)=\left[\begin{array}{cccccc}
M_{11} & M_{12} & M_{13} & 0 & 0 & 0 \\
M_{12} & M_{22} & M_{23} & 0 & 0 & 0 \\
M_{13} & M_{23} & M_{33} & 0 & 0 & 0 \\
0 & 0 & 0 & 2 M_{44} & 0 & 0 \\
0 & 0 & 0 & 0 & 2 M_{55} & 0 \\
0 & 0 & 0 & 0 & 0 & 2 M_{66}
\end{array}\right]_{\left(\underline{u}_{i}\right)}
$$

with $M_{11}=a_{1} / \sigma_{\text {longi }}^{2}+\left(a_{2}+a_{3}\right) / \sigma_{\text {transv }}^{2} \cdot M_{22}$ and $M_{33}$ are obtained by circular permutations on subscripts $i=$ 1, 2,3 from the expression of $M_{11}$, and $M_{44}=\left(a_{1}+a_{2}\right) / \tau_{\text {longi }}^{2}, M_{55}=\left(a_{1}+a_{3}\right) / \tau_{\text {longi }}^{2}, M_{66}=\left(a_{2}+a_{3}\right) / \tau_{\text {longi }}^{2}$. At last, according to Hill's theory, $M_{12}, M_{13}$ and $M_{23}$ are determined with the relationships $M_{i 1}+M_{i 2}+M_{i 3}=0$ for $i=1,2,3$. Note that $G_{\mathrm{T}-\mathrm{H}}$ is dimensionless. The fatigue model is eventually expressed as follows:

$$
G_{\mathrm{T}-\mathrm{H}}^{a} \cdot N_{r}^{b}=1
$$

As explained in Annexe A, $G_{\mathrm{T}-\mathrm{H}}^{a}$ is the amplitude of $G_{\mathrm{T}-\mathrm{H}}(t)$ over one cycle. The calibration of the present formulation only requires four material parameters ( $\sigma_{\text {longi }}, \sigma_{\text {transv }}, \tau_{\text {longi }}$ and the slope $\left.b\right)$, which are assumed to be independent on the microstructure (defined by the orientation tensor $\underline{\underline{a}}^{\psi}$ ).

\subsubsection{Principal stress/strain amplitude}

The principal stress criterion is formulated with the amplitude of the highest stress eigenvalue $\sigma_{\text {princ }}$ over the stabilized cycle. It may be written as:

$$
\log N_{r}=\frac{\sigma_{0}-\left(\sigma_{\text {princ }}^{a}\right)}{b}
$$

Klimkeit et al. [32] have already shown that such a criterion ${ }^{3}$ is not predictive, and very non-conservative on pure torsion tests. $\sigma_{\text {princ }}^{a}$ is thus expected to be poorly correlated to the fatigue life.

It is also possible to propose a similar criterion with the principal strain. As suggested by Mourglia Seignobos [10], the principal strain may be well correlated to the fatigue duration. In her work, only tensile specimen have been tested, but in different environmental conditions. This criterion reads :

$$
\log N_{r}=\frac{\varepsilon_{0}-\left(\varepsilon_{\text {princ }}^{a}\right)}{b}
$$

\footnotetext{
${ }^{3}$ More specifically, the principal stress criterion used in [32] is formulated with a power law, i.e. linear in log-log rather than in log-lin diagram. But the existence of a potential correlation between the principal stress amplitude and the fatigue life does not depend on the chosen representation.
} 


\subsection{Inelastic strain and energy based models}

\subsubsection{Manson-Coffin model}

The Manson-Coffin equation has been originally proposed for predicting the LCF life of metallic materials in uniaxial tests [43, 44], and reads:

$$
\varepsilon_{v p}^{a} \cdot N_{r}^{b}=C
$$

where $\varepsilon_{v p}^{a}$ is the amplitude of (visco-)plastic strain along the loading direction during a cycle. $b$ and $C$ are two model parameters. If this criterion is suitable, $\varepsilon_{v p}^{a}$ is represented by a straight line when plotted as a function of $N_{r}$ in a log-log diagram. This model has been extended for multiaxial loadings by measuring the radius of the smallest hypersphere circumscribing the loading path in the 5 -dimension plastic strains space ${ }^{4}$ [34]:

$$
\varepsilon_{v p}^{a}=\min _{\underline{\underline{e}}_{1}} \max _{t \in\left[0, T_{\text {cycle }}\right]}\left[\sqrt{\frac{2}{3}\left(\underline{\underline{e}}_{1}-\underline{\underline{\varepsilon}}_{v p}(t)\right):\left(\underline{\underline{e}}_{1}-\underline{\underline{\varepsilon}}_{v p}(t)\right)}\right]
$$

\subsubsection{Criteria based on energy considerations}

Morrow [45] proposed to correlate the fatigue life to the dissipated energy density per cycle. This criterion in based on a scalar quantity, and is thus easily computed for multiaxial loadings. It has been successfully validated later by Skelton [46] for LCF loadings at high temperature on metallic alloys, and Charkaluk and Constantinescu [47] for the thermomechanical fatigue of cast-iron. Such a criteria is written as follows:

$$
\Delta W_{\mathrm{diss}} \cdot N_{r}^{b}=C
$$

$\Delta W_{\text {diss }}$ is the energy density dissipated by plastic mechanisms in one cycle, in steady-state regime. In that case, as the elastic strain is reversible, this quantity may be computed as:

$$
\Delta W_{\text {diss }} \equiv \int_{\text {cycle }} \underline{\underline{\sigma}}(t): \dot{\underline{\varepsilon}}_{v p}(t) \mathrm{d} t=\int_{\text {cycle }} \underline{\underline{\sigma}}: \mathrm{d} \underline{\underline{\varepsilon}}
$$

Amiable et al. [48] proposed an extension of this criterion to better take into account the effects of load ratio. To model the fact that opened micro-cracks are more critical than closed ones, they added a dependency to the maximal hydrostatic stress per cycle:

$$
\left(\Delta W_{\text {diss }}+\alpha P_{\max }\right) \cdot N_{r}^{b}=C
$$

In the case of our material, we could also split the dissipated energy according to its different contributions. The proposed constitutive equations indeed result into the expression of the instantaneous dissipation

\footnotetext{
${ }^{4}$ This min-max problem gives the same results as the max-max problem presented in Eq. ?? for all loading cases studied in this paper, but avoids numerical indetermination for some very specific loading histories.
} 
integrated over one cycle:

$$
\begin{aligned}
\Delta W_{\text {diss }} & =\int_{\text {cycle }} \mathscr{D}(t) \mathrm{d} t \\
& =\int_{\text {cycle }} \underbrace{\underline{\underline{\mathcal{A}}}_{v 1}: \underline{\underline{\underline{\varepsilon}}}_{v 1}(t)+\underline{\underline{\mathcal{A}}}_{v 2}: \dot{\underline{\varepsilon}}_{v 2}(t)}_{\text {viscoelastic dissipation }}+\underbrace{\underbrace{\mathcal{A}}_{v p}: \dot{\underline{\varepsilon}}_{v p}(t)+\underline{\underline{X}}: \underline{\underline{\dot{\alpha}}}(t)}_{\text {viscoplastic diss. }}+\underbrace{\mathcal{A}_{\beta} \cdot \dot{\beta}(t)}_{\text {softening diss. }} \mathrm{d} t \\
& \equiv \Delta W_{v e}+\Delta W_{v p}+\Delta W_{s}
\end{aligned}
$$

The energy dissipated by softening is negligible for a stabilized cycle. An alternative to the energy criterion is a combination of viscoelastic and viscoplastic dissipated energies with different weights, such as:

$$
\left(\Delta W_{v p}+\alpha \Delta W_{v e}\right) \cdot N_{r}^{b}=C
$$

In the limit case $\alpha=0$, the dissipated energy by viscoplastic mechanisms is the only physical quantity correlated to the fatigue life. At the opposite, $\alpha=1$ corresponds to the previous energetic model.

\section{Results and discussion}

In this section, the previous fatigue lifetime models are evaluated on De Monte's and Klimkeit's database, i.e. for the DAM and conditioned (RH50) material states. For each criteria, the reader may refer to Tab. 3 for the values of the identified model parameters (continuous or dotted lines plotted in each figure), and for the references of the equations.

\subsection{Results for stress based fatigue models}

In Fig. 6, the number of cycles to failure is plotted versus a measure of the shear-stress, for both materials (RH50 and DAM). As mentioned by Klimkeit et al. [3], the von Mises criterion displays a poor correlation with $N_{r}$ on the conditioned material (it is notably very non-conservative for dogbone specimen at $90^{\circ}$ ). This observation is also made for dry material on De Monte's tests. In Figs. 6c and 6d, the shear-stress is computed with the anisotropic Hill norm. This modification of the norm in order to take into account the effect of microstructure on fatigue mechanisms is obviously not sufficient, and the criterion is still not predictive. However, the tests performed at $R=-1$ (mean hydrostatic stress equals 0 ) and torsion tests (no pressure) present less scatter than for the von Mises criterion. This is the reason why, in the following, the Hill norm will be preferred to the von Mises norm for criteria involving shear-stress.

A possible improvement in order to take into account mean-stress effects with a shear-stress criterion is to combine it with a measure of the hydrostatic stress. Figure 7 compares three different criteria which are extensions of the classical Crossland, Sines and Dang Van criteria. As noted previously, the Sines criterion gives the best results because torsion and fully-reversed $(R=-1)$ tests are already well correlated with the 


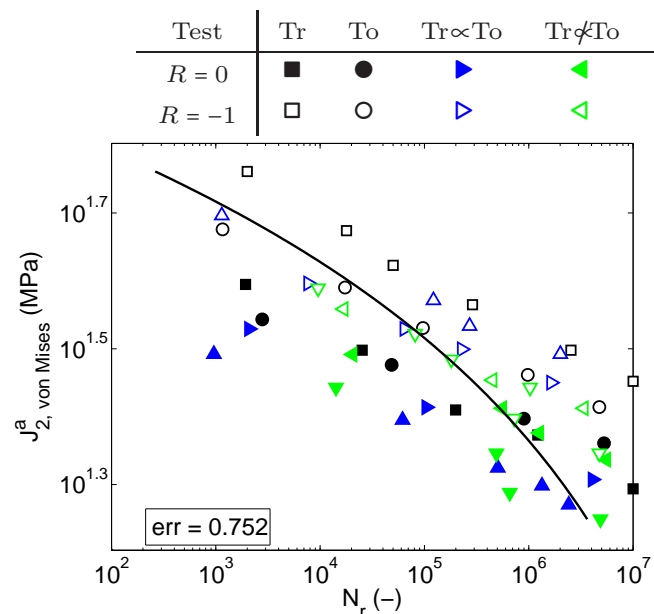

(a) Shear-Stress, von Mises (DAM)

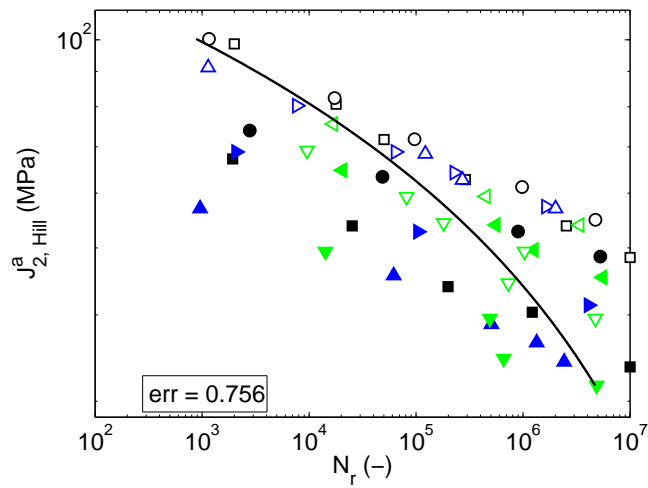

(c) Shear-Stress, Hill (DAM) \begin{tabular}{ccccc}
$3 \operatorname{Tr} \propto \operatorname{To}$ & $3 \operatorname{Tr} \propto T$ To & $2 \operatorname{Tr} \propto \operatorname{To}$ & $\operatorname{Tr} \|$ & $\operatorname{Tr} \perp$ \\
\hline $\boldsymbol{\Delta}$ & $\nabla$ & $\boldsymbol{\Delta}$ & $\square$ & $\square$ \\
$\Delta$ & $\nabla$ & $\Delta$ & $\square$ & $\square$
\end{tabular}

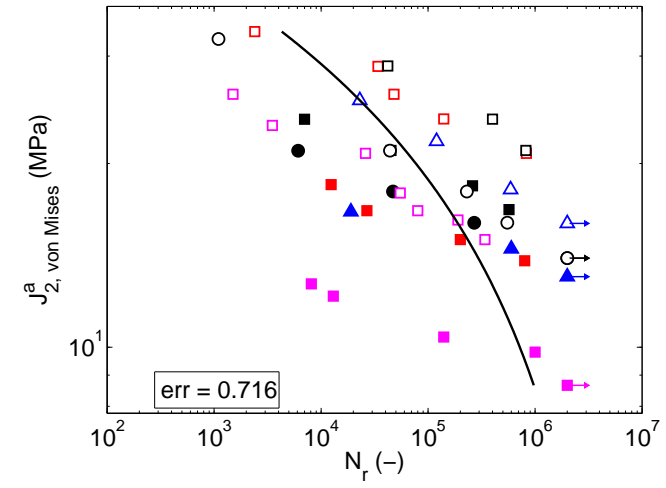

(b) Shear-Stress, von Mises (RH50)

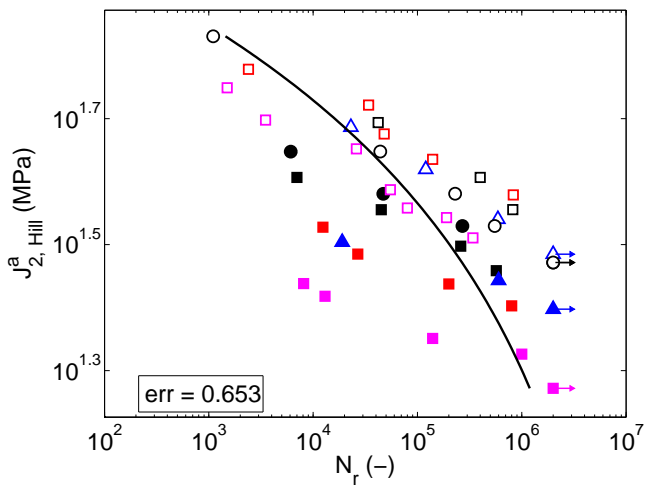

(d) Shear-Stress, Hill (RH50)

Figure 6: Results for shear-stress criteria on De Monte's database $\left(23^{\circ} \mathrm{C}\right.$, DAM - left $)$ and on Klimkeit's database $\left(23^{\circ} \mathrm{C}, \mathrm{RH} 50\right.$ - right). The two points displayed at $N=10^{7}$ cycles on dry material (left) are run-out tests. 
Hill shear-stress criterion. Even if the results are better than for a mere shear-stress criterion, Crossland and Dang Van criteria do not stand for satisfying multiaxial criteria. However, the Sines criterion could be considered as quite predictive for the DAM material, but not for conditioned one. On the latter, the tests for which the correlation is the worse are the repeated tensile tests on dogbones milled out of injected plates. It is possible that the Sines criterion is appropriate for describing loading multiaxiality, but not variations of the microstructure.

In Fig. 8, the results given by the proposed modified Tsai-Hill criterion are displayed for both materials. First of all, one can see that this fatigue model (identified on the whole databases) leads to poor estimations, notably because tests at $R=0$ and $R=-1$ are not well correlated to each others. Even if the proposed modified Tsai-Hill criterion is not formulated in the same way, De Monte et al. [11] faced a similar issue, which explains why they determined a set of model parameters for each value of the load ratio $R$. We did not make the same choice, since criteria with too many parameters are not compatible with industrial requirements. If one looks closer at the results, it appears that the modified Tsai-Hill criterion describes very well, as expected, the influence of the fibre orientation on fatigue life when the load ratio is constant (dogbones at 0 and $90^{\circ}$ - see results on Klimkeit's database). But the correlation between $G_{T-H}^{a}$ and $N_{r}$ becomes poor when multiaxial tests (especially with out-of-phase tension-torsion signals) are part of the database. This is obvious on De Monte's database.

Let us remark that similar criteria have been applied to continuous fibre laminates under multiaxial fatigue with fairly good results by Quaresimin et al. [49]: present life estimations given by the modified Tsai-Hill criterion may therefore be surprisingly disappointing. However, De Monte et al. [4] showed that a variation of phase angle $\delta$ affects significantly the fatigue duration of SGFR thermoplastics, which is not the case of materials studied in [49], and explains our results ${ }^{5}$.

Other classical criteria for multiaxial HCF tests are built on the principal stress or strain amplitudes (see results in Fig. 9). As demonstrated by Klimkeit et al. [3], the principal stress is relevant neither for conditioned material, nor for the dry material. The principal strain criterion seems interesting on fullyreversed tests, especially on conditioned material. However, it is not suitable for the tests performed at $R=0$. A correction involving the hydrostatic stress (in the same way as Sines or Crossland criteria) may be a way of improvement; yet, this idea does not bring significant success and is not pursued.

\footnotetext{
${ }^{5}$ A modified Tsai-Hill criterion is also proposed by Jen et al. [50, 51] for continuous carbon fibre/thermoplastic laminates, as reviewed by Degrieck and Van Paepegem [52]. The authors present good estimations of fatigue life, but their fatigue database only involves in-phase multiaxial loadings, which is the reason why their work is not further discussed.
} 


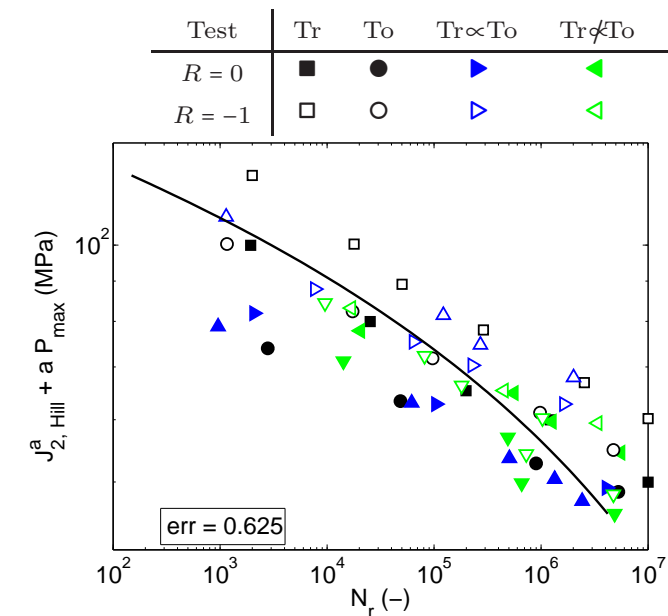

(a) Crossland (DAM)

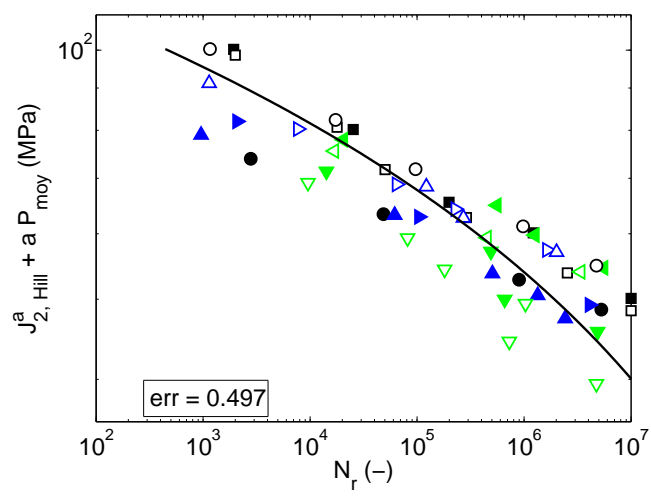

(c) Sines (DAM)

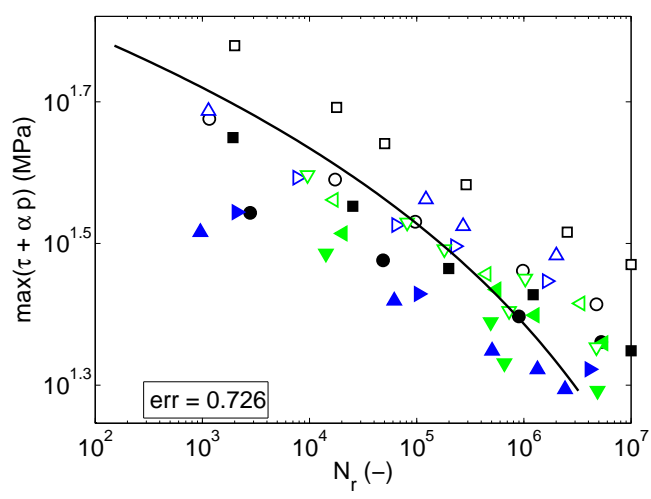

(e) Dang Van (DAM)

\begin{tabular}{ccccc}
$3 \operatorname{Tr} \propto \operatorname{To}$ & $3 \operatorname{Tr} \propto \operatorname{To}$ & $2 \operatorname{Tr} \propto \operatorname{To}$ & $\operatorname{Tr} \|$ & $\operatorname{Tr} \perp$ \\
\hline $\mathbf{\Delta}$ & $\nabla$ & $\mathbf{\Delta}$ & $\square$ & $\square$ \\
$\Delta$ & $\nabla$ & $\Delta$ & $\square$ & $\square$
\end{tabular}

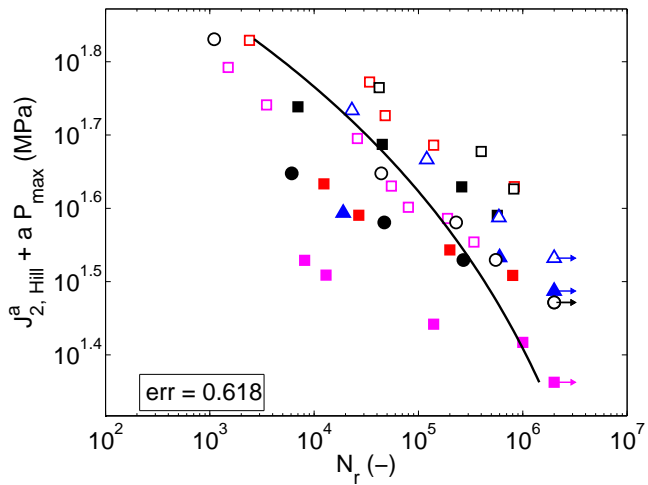

(b) Crossland (RH50)

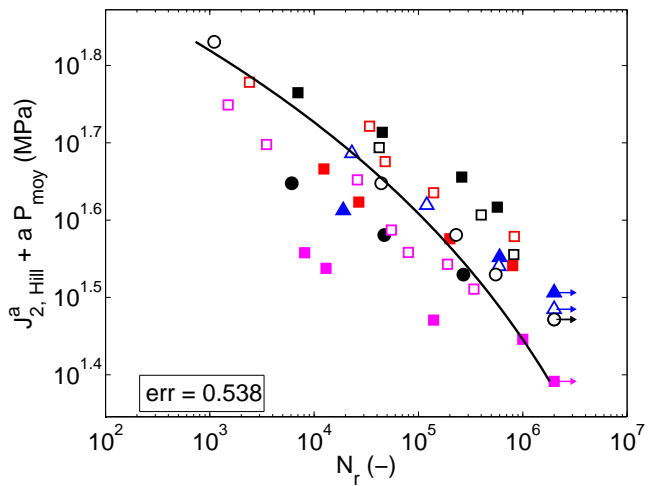

(d) Sines (RH50)

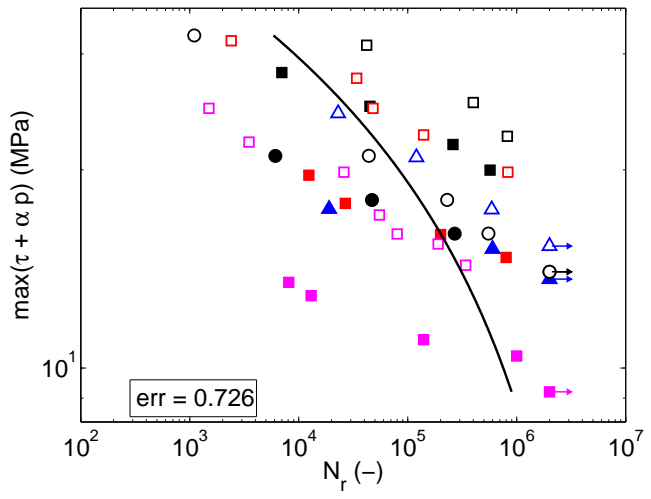

(f) Dang Van (RH50)

Figure 7: Results for different HCF criteria combining shear and hydrostatic stress. 

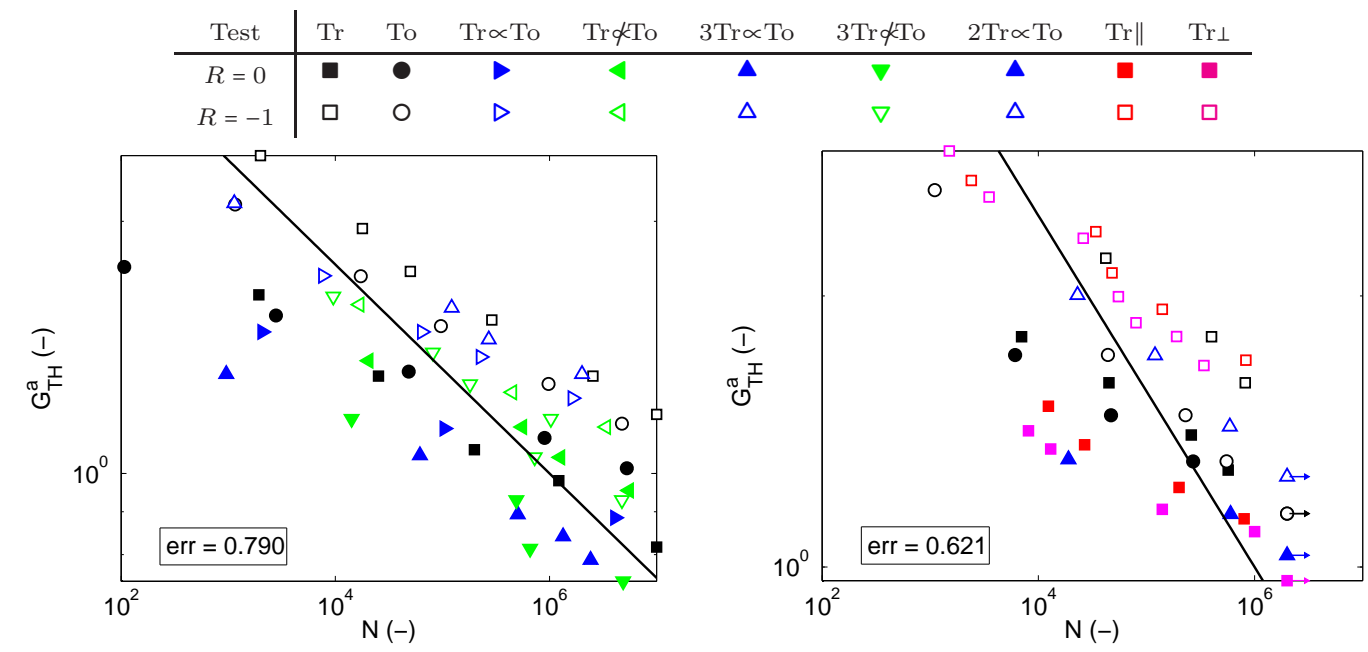

Figure 8: Results for the modified Tsai-Hill criterion, on DAM (left) and RH50 (right) materials.

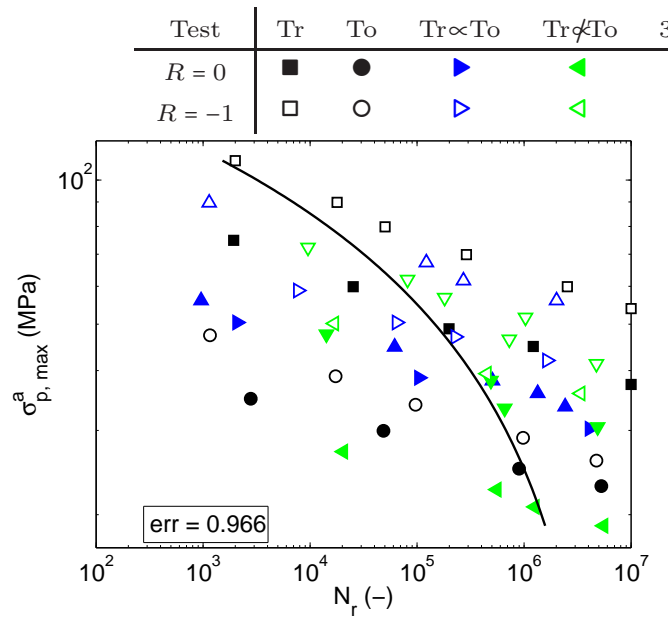

(a) Principal Stress (DAM)

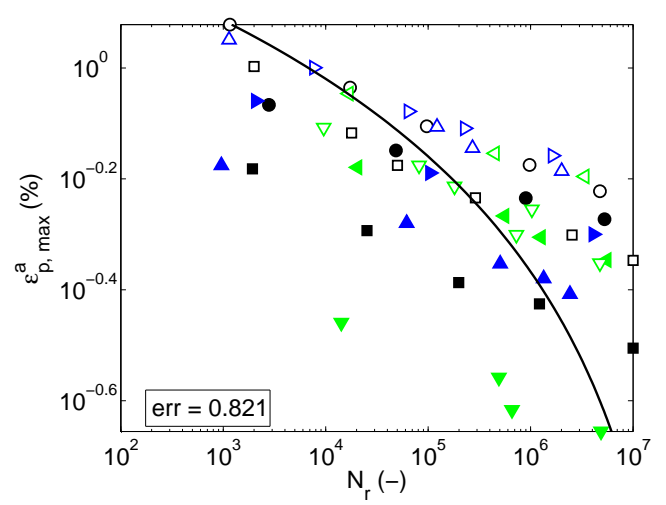

(c) Principal Strain (DAM)

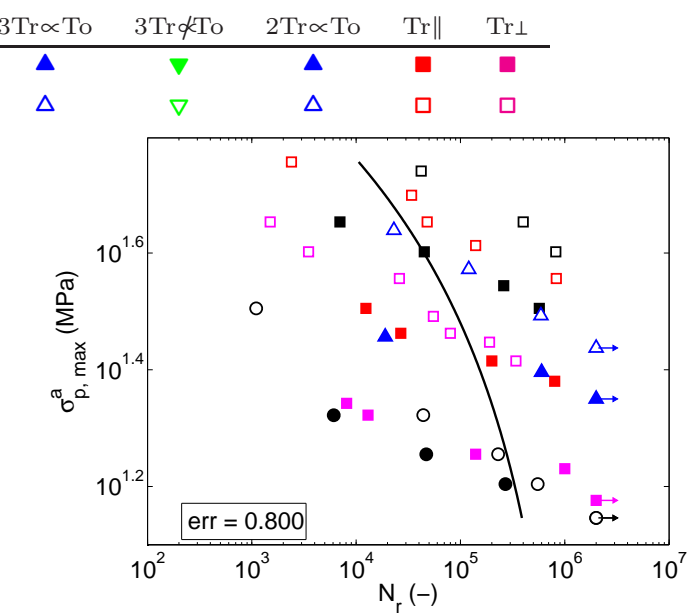

(b) Principal Stress (RH50)

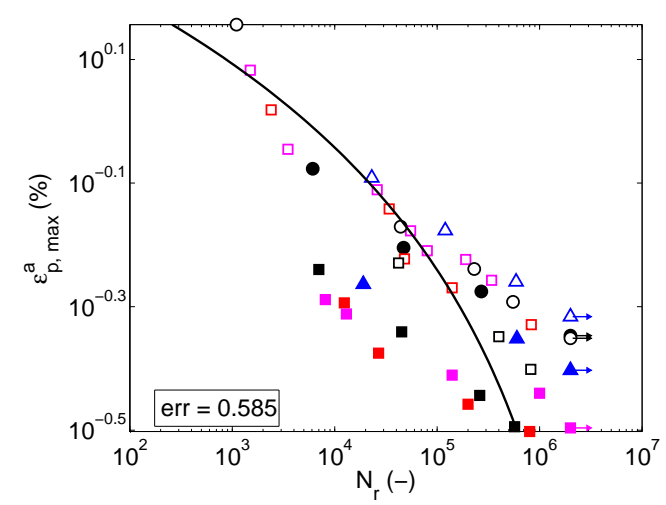

(d) Principal Strain (RH50)

Figure 9: Results for criteria based on principal stress/strain amplitude. 


\subsection{Results for inelastic strain and energy fatigue models}

Among the LCF fatigue criteria, the Manson-Coffin criterion is commonly used for metallic materials. Nevertheless, this criterion does not appear to be relevant for reinforced polyamide in dry or conditioned state. Even for the lowest fatigue durations, for which a LCF criterion should be the most appropriate, the amplitude of viscoplastic strain is poorly correlated to the fatigue life (see Fig. 10). At last, the constitutive model predicts very small values of $\varepsilon_{v p}^{a}$ at low stress levels, and we can wonder if these values are representative enough for being an indicator of the fatigue damage.

On the other hand, Fig. 11 displays the results obtained with the energy criterion and its variants. At first, the dissipated energy per cycle $\Delta W_{\text {diss }}$ is plotted versus the number of cycles to failure, and a good correlation is observed on DAM and RH50 material. Despite this interesting results, a more specific analysis indicates that the tests which display the worse correlation are subjected to high torsion loading in the case of dry material. In the case of conditioned material, the energy criterion systematically overestimates the fatigue duration of tensile tests performed on dogbones milled out at $90^{\circ}$.

Amiable criterion is a variant of the energy criterion which takes into account the influence of the hydrostatic stress. In our study, this influence seems to be negligible on both De Monte's and Klimkeit's databases. No significant improvement stems from this extension of the energy criterion, which is consistent with the identified weighting coefficient $\alpha$.

The modified energy criterion aims at distinguishing the role played by the viscoelastic and the viscoplastic parts on the overall dissipated energy. A slight improvement on the prediction of the fatigue duration is shown, notably on DAM material. The identified coefficient $\alpha$ is quite high (see Tab. 3), which shows that the energy dissipated by viscoelastic mechanisms should be an indicator of fatigue damage. This is not surprising, because it is well known on metallic materials that an overall elastic response may be elastoplastic at a smaller scale [53]; this dissipation source being correlated to fatigue damage. In the case of polymeric materials, an apparent viscoelastic response may be viscoplastic at a smaller scale, where fatigue mechanisms occur. We can also assess that the energy dissipated by viscoplastic mechanisms $\Delta W_{v p}$ cannot by itself be correlated to fatigue damage over such a wide range of fatigue durations: forcing the condition $\alpha=0$ leads indeed to poor correlations.

\subsection{Performance of the different models and discussion}

Among the stress based fatigue models, the shear-stress criteria are poorly correlated to the fatigue duration. They notably fail to reproduce mean-stress effects. Taking into account the mean hydrostatic stress (Sines criterion) leads to a significative improvement on DAM material, but not on RH50 material. The principal stress criteria is shown to be non-relevant, whereas the principal strain criterion could only be interesting for fully-reversed tests. The modified Tsai-Hill criterion leads to an important number of model 


\begin{tabular}{c|ccccccccc} 
Test & $\operatorname{Tr}$ & To & $\operatorname{Tr} \propto$ To & $\operatorname{Tr} \propto$ To & $3 \operatorname{Tr} \propto$ To & $3 \operatorname{Tr} \propto$ To & $2 \operatorname{Tr} \propto$ To & $\operatorname{Tr} \|$ & $\operatorname{Tr} \perp$ \\
\hline$R=0$ & $\square$ & $\bullet$ & $\triangleright$ & $\triangleleft$ & $\Delta$ & $\nabla$ & $\Delta$ & $\square$ & $\square$ \\
$R=-1$ & $\square$ & 0 & $\triangleright$ & $\triangleleft$ & $\Delta$ & $\nabla$ & $\Delta$ & $\square$ & $\square$
\end{tabular}
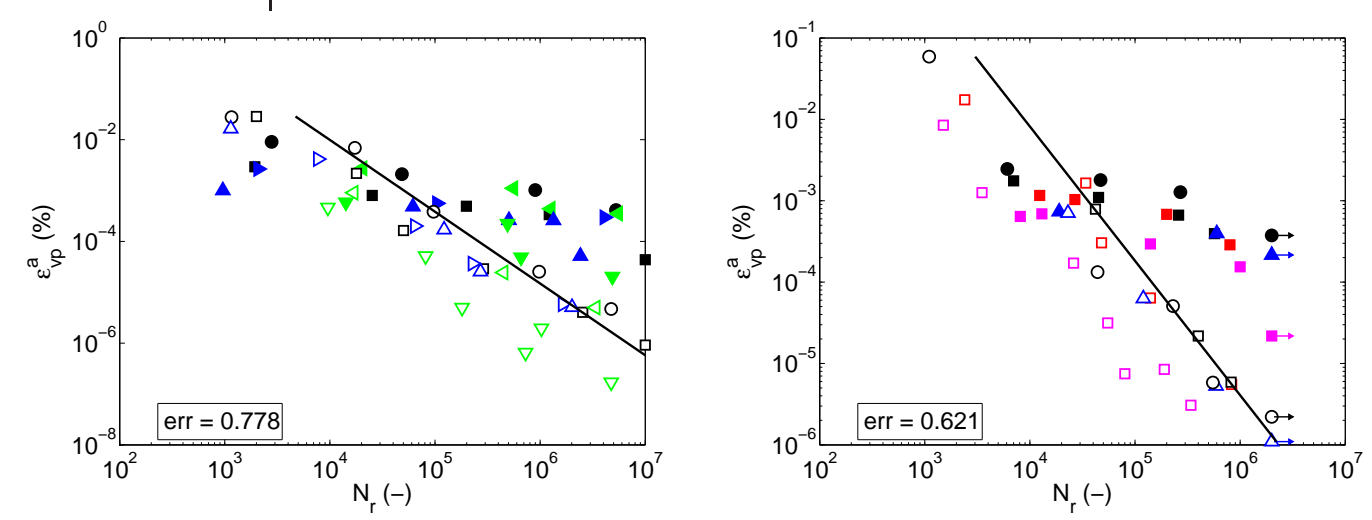

Figure 10: Results for the Manson-Coffin criterion, on DAM (left) and RH50 (right) materials.

parameters, and yet fails to properly estimate the fatigue life under complex multiaxial effects. Moreover, describing the influence of mean-stress effects through different sets of coefficients according to $R$ is not convenient for industrial applications.

The Manson-Coffin criterion does not seem to be relevant for SGFR polyamides. At the opposite, the criterion based on the dissipated energy density offers a fairly good agreement with experimental data in both DAM and RH50 conditions. It leads to correct life estimations under multiaxial loadings, and it is suitable for different load ratios and different microstructures. The so-called energy criterion is not improved by taking into account the hydrostatic stress (Amiable's criterion). On the other hand, weighting viscoplastic and viscoelastic contributions to the whole dissipation brings a slight improvement (modified energy criterion). However, we consider that without more discriminative tests, it is not worth the introduction of an additional parameter in the fatigue model.

One should be aware that the appropriate choice of one physical quantity to be correlated to the fatigue life is possible only if the first step of our approach for fatigue design, i.e. the computation of the cyclic response, is reliable. Fatigue tests are load-controlled, which means that physical quantities based on the local stress tensor are well known. Moreover, as already mentioned in Part I of this work, the proposed constitutive equations provide a fairly accurate estimation of the dissipated energy density, which has also been experimentally shown to reach a stationary state in a few cycles. If creep-fatigue coupling occurs, an evolution of the mean strain tensor $\left(\underline{\underline{\varepsilon}}^{*}\right)$ may be superimposed to the cyclic strain response. Consequently, the fatigue model should probably account for both the maximum strain and the dissipated energy density per cycle. This is a possible improvement of the present approach.

Besides, some loading conditions investigated by Klimkeit et al. as well as De Monte et al. really differ 


\begin{tabular}{c|ccccccccc} 
Test & $\operatorname{Tr}$ & To & $\operatorname{Tr} \propto$ To & $\operatorname{Tr} \propto \operatorname{To}$ & $3 \operatorname{Tr} \propto$ To & $3 \operatorname{Tr} \propto$ To & $2 \operatorname{Tr} \propto \operatorname{To}$ & $\operatorname{Tr} \|$ & $\operatorname{Tr} \perp$ \\
\hline$R=0$ & $\square$ & $\bullet$ & $\triangleright$ & $\triangleleft$ & $\Delta$ & $\nabla$ & $\Delta$ & $\square$ & $\square$ \\
$R=-1$ & $\square$ & $\bigcirc$ & $\triangleright$ & $\triangleleft$ & $\Delta$ & $\nabla$ & $\Delta$ & $\square$ & $\square$
\end{tabular}

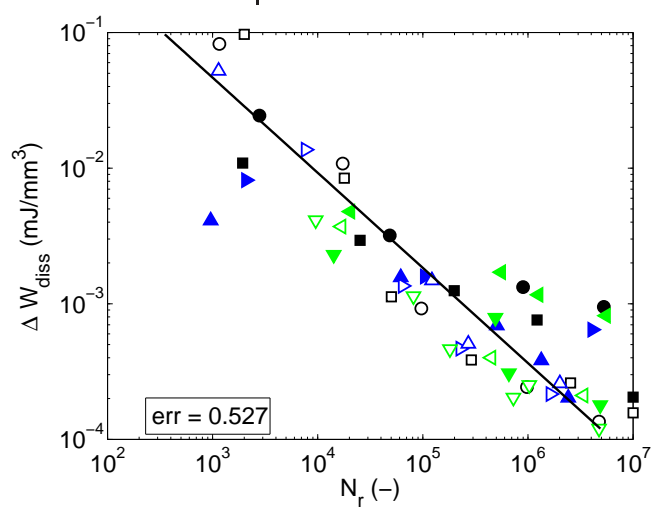

(a) Energy (DAM)

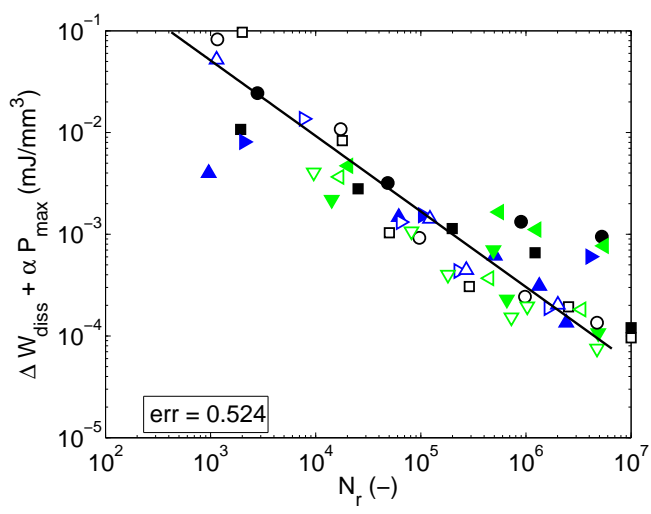

(c) Amiable (DAM)

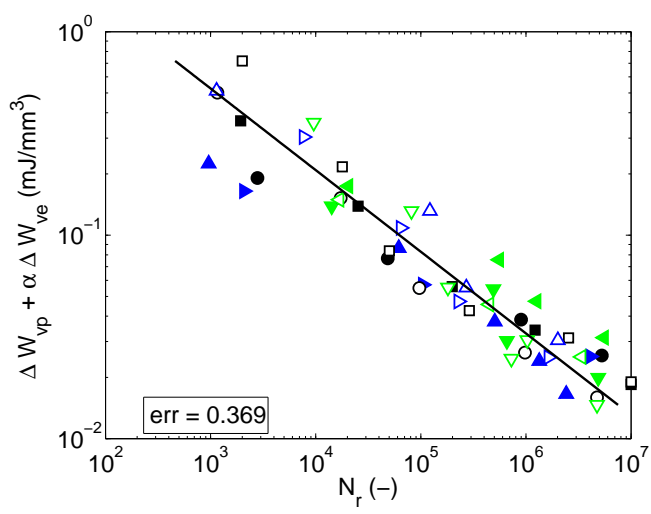

(e) Modified energy (DAM)

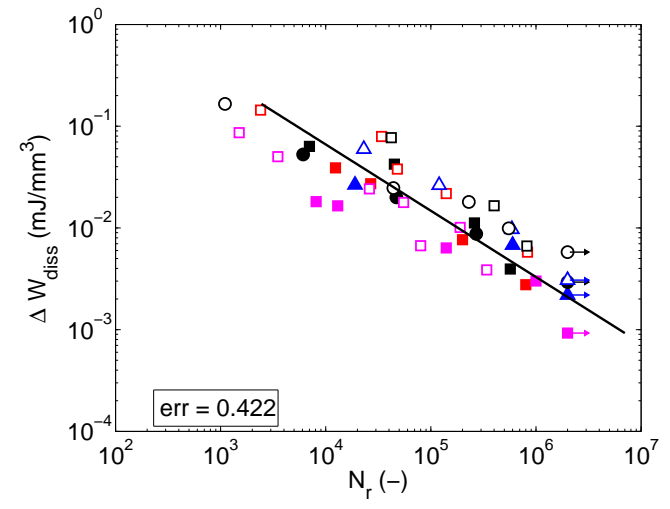

(b) Energy (RH50)

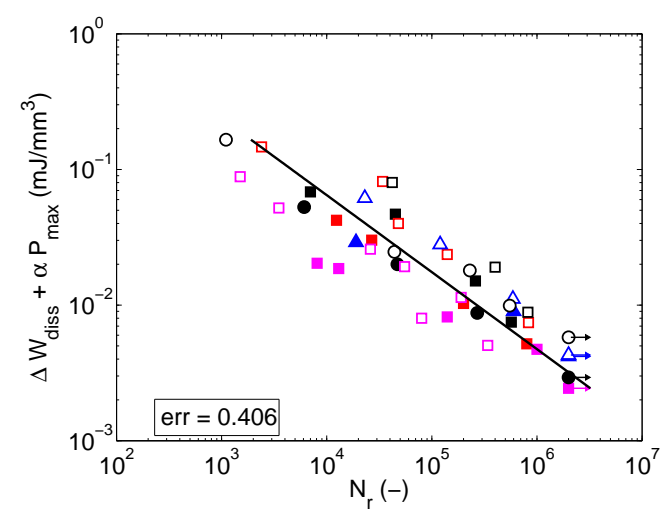

(d) Amiable (RH50)

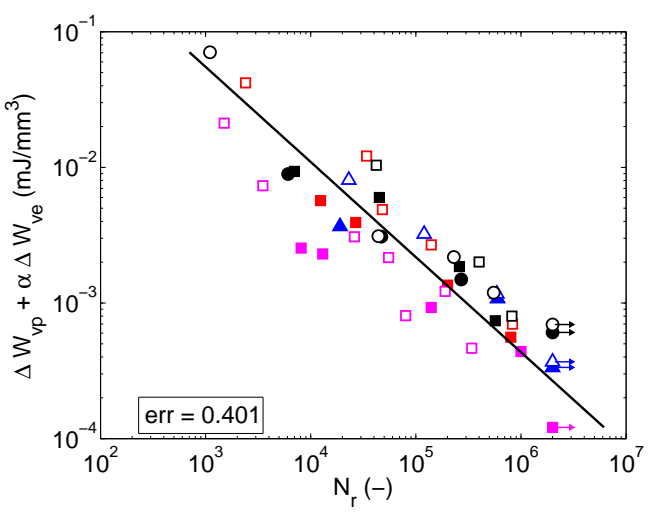

(f) Modified energy (RH50)

Figure 11: Results for the energy criterion and its variants. 
from the static tests performed for the identification of the material parameters. Torsion tests are indeed directly linked to local shear, whereas no shear test is part of the identification strategy. It would therefore be interesting to compare numerical and experimental mechanical responses under static tests on e.g. Iosipescu samples [32] (unfortunately, such experimental data is not published in the literature). At last, questions regarding the computation of the mechanical behaviour also involve uncertainties about exact test frequencies, accurate orientation fields in samples or material parameters due to the different grades of PA66-GF35: these points should be addressed to deepen the discussion about the fatigue criteria comparison.

In Fig. 12, we compare the performance of the energy criterion with the criterion proposed by Klimkeit et al. [3] on the same database. Klimkeit's criterion relies on the elastic strain energy, and is, to the authors' knowledge, the only criterion dedicated to multiaxial fatigue suggested in the literature for SGFR thermoplastics. It also only involves two model parameters. The fatigue life estimated with the proposed energy criterion is closer to experimental data for all test conditions. This is explained by the use of the proposed constitutive model which describes the dissipation sources. Hence, relevant local mechanical quantities, potentially correlated to fatigue mechanisms, are computed. The dissipated energy density at the macroscopic scale may indeed be interpreted as the signature of nonlinear local mechanisms (matrix plastification, fibre-matrix debonding, cavitation around fibre tips...) which are directly linked to fatigue damage. Such a comparison demonstrates the interest of our whole approach, from the need of an accurate constitutive model for the cyclic behaviour, to the choice of a relevant physical value correlated to the fatigue life.

\section{Conclusions}

A phenomenological constitutive model has been applied to compute the local mechanical response of PA66-GF35 under fatigue loadings presented in the literature. A comparison of different classical fatigue models inspired from LCF or HCF criteria has been made. From this work performed for two environmental conditions (DAM and RH50), it results that the dissipated energy density per cycle $\Delta W_{\text {diss }}$ gives a satisfying prediction of the lifetime $N_{r}$. This criterion describes multiaxiality and load ratio effects, as well as the influence of the microstructure, for lifetimes from thousands to millions of cycles.

Despite we are not provided with all the information required for a very accurate computation of the cyclic mechanical response, the simulation of the fatigue tests of De Monte's and Klimkeit's databases are considered as reliable. The energy criterion, based on the dissipated energy density per cycle, leads to better lifetime estimations than any other fatigue criterion we tested. The comparison with Klimkeit's criterion reveals its predictivity and demonstrates the relevancy of describing the nonlinear features of the mechanical cyclic response for fatigue applications. 


\begin{tabular}{c|ccccc} 
Test & Tr & To & $2 \operatorname{Tr} \propto$ To & $\operatorname{Tr} \|$ & $\operatorname{Tr} \perp$ \\
\hline$R=0$ & $\square$ & $\bullet$ & $\boldsymbol{\Delta}$ & $\square$ & $\square$ \\
$R=-1$ & $\square$ & $\bigcirc$ & $\Delta$ & $\square$ & $\square$
\end{tabular}

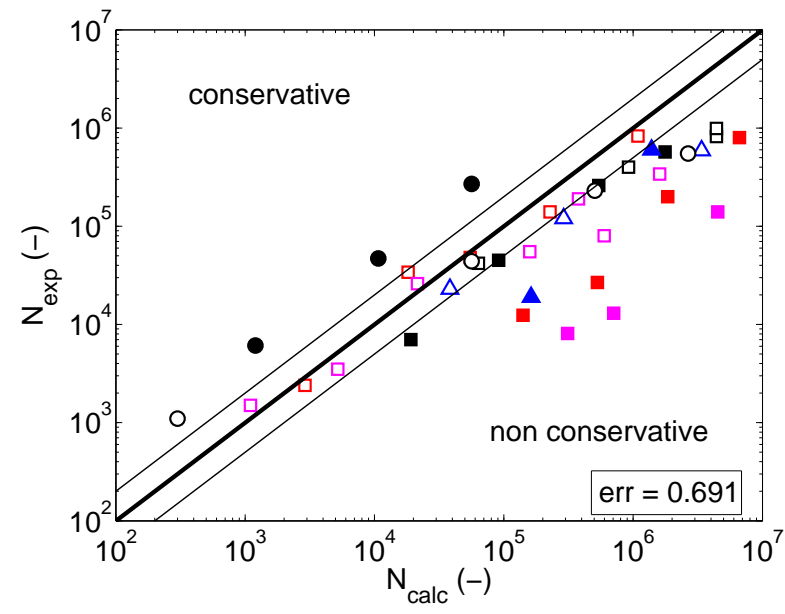

(a) Klimkeit's criterion

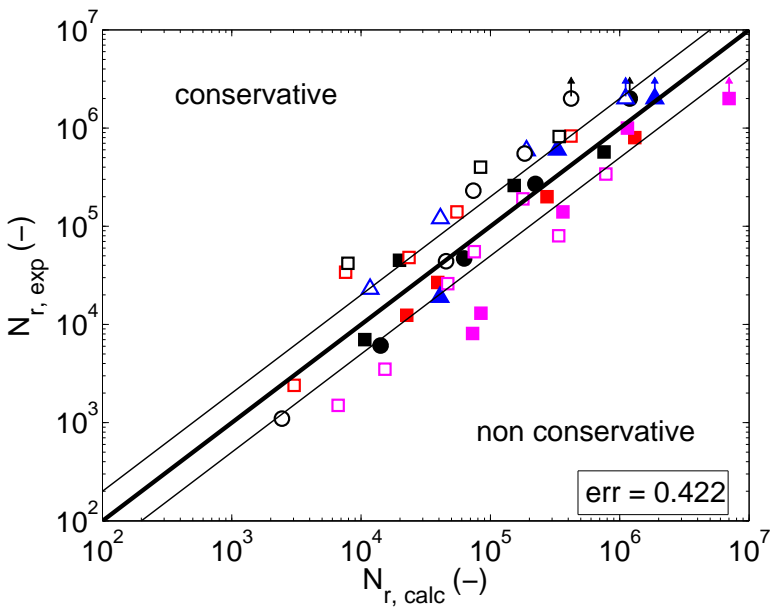

(b) Energy criterion

Figure 12: Comparison of the criterion proposed by Klimkeit et al. [3] with the energy criterion, computed with the proposed constitutive behaviour $\left(\mathrm{RH} 50,23^{\circ} \mathrm{C}\right)$.

The first outlook of this work lies in the better understanding of the physical mechanisms that lead to failure at a microstructural scale. It could physically assess the choice of one specific mechanical quantity to be an indicator of the fatigue damage. For example, the proposed energy criterion is formulated at the macroscopic scale, but a description at the skin/core scale could improve the fatigue life estimations. Besides, the energy criterion should be validated on different loading histories, e.g. involving different waveforms, creep or relaxation steps, and has to be investigated on industrial components.

\section{Acknowledgement}

This work was supported by PSA Peugeot-Citroën and has received the financial support of the French Minister for Research (ANRT).

\section{Annexe A. Proposition of a new modified Tsai-Hill fatigue criterion}

This appendix explains how is built the modified Tsai-Hill criterion used in Sections 4.3.3 and 5.1.

The classical Tsai-Hill criterion for static strength of anisotropic materials stems from Hill [42]'s plasticity theory for anisotropic metals, and is generally written $[54,55]$ :

$$
H\left(\sigma_{11}-\sigma_{22}\right)^{2}+F\left(\sigma_{22}-\sigma_{33}\right)^{2}+G\left(\sigma_{33}-\sigma_{11}\right)^{2}+N \sigma_{12}^{2}+P \sigma_{13}^{2}+Q \sigma_{23}^{2}=1
$$


$\mathrm{H}, \ldots \mathrm{Q}$ are 6 material parameters. Remark that such a formulation is pressure insensitive, and is strictly equivalent to the following equation:

$$
G_{\mathrm{T}-\mathrm{H}}^{2} \stackrel{\text { def }}{=} \underline{\underline{\sigma}}: \mathbb{M}: \underline{\underline{\sigma}}=1
$$

where $\mathbb{M}$ is a fourth-order material tensor, which can be represented by a $6 \times 6$ matrix according to Voigt's notations:

$$
\mathbb{M}=\left[\begin{array}{cccccc}
G+H & -G & -H & 0 & 0 & 0 \\
-G & F+H & -F & 0 & 0 & 0 \\
-H & -F & F+G & 0 & 0 & 0 \\
0 & 0 & 0 & 2 N & 0 & 0 \\
0 & 0 & 0 & 0 & 2 P & 0 \\
0 & 0 & 0 & 0 & 0 & 2 Q
\end{array}\right]
$$

For a unidirectional composite, with $\underline{e}_{1}$ as principal axis, this tensor should respect the transverse isotropic symmetries: $G=H, N=P$. In the plane stress case $\left(\sigma_{13}=\sigma_{23}=\sigma_{33}=0\right)$, one can define:

$$
\begin{aligned}
\sigma_{\text {longi }}^{2} & =\frac{1}{G+H}=\frac{1}{2 G} \\
\sigma_{\text {transv }}^{2} & =\frac{1}{F+H} \\
\tau_{\text {longi }}^{2} & =\frac{1}{N}
\end{aligned}
$$

which leads to the very classical equation:

$$
\left(\frac{\sigma_{11}}{\sigma_{\text {longi }}}\right)^{2}+\left(\frac{\sigma_{22}}{\sigma_{\text {transv }}}\right)^{2}-\frac{\sigma_{11} \sigma_{22}}{\sigma_{\text {longi }}^{2}}+2\left(\frac{\sigma_{12}}{\tau_{\text {longi }}}\right)^{2}=1
$$

This equation has been generalized to predict fatigue life duration of composite materials, replacing the parameters indicating static strengths by Basquin equations depending on the number of cycles to failure $N_{r}[11,15,56,57]$

$$
\left(\frac{\sigma_{11}}{S_{l}\left(N_{r}\right)}\right)^{2}+\left(\frac{\sigma_{22}}{S_{t}\left(N_{r}\right)}\right)^{2}-\frac{\sigma_{11} \sigma_{22}}{S_{l}\left(N_{r}\right)^{2}}+2\left(\frac{\sigma_{12}}{T_{l}\left(N_{r}\right)}\right)^{2}=1
$$

with for instance $S_{l}\left(N_{r}\right)=S_{l}^{0} N_{r}^{-1 / \beta_{l}}$. As aforementioned, such generalization offers a major drawback in the case of SGFR composites, since materials parameters are only valid for one FOD. Moreover, 6 material parameters are to be identified in the plane stress case, or at least 4 if the slope $\beta$ is assumed identical for the three Basquin equations. That is the reason why we consider that this formulation, even if promising on tensile samples milled out of plates at different angles [11], does not seem suitable for estimating the fatigue life of industrial structures.

In the case of SGFR thermoplastics, the local microstructure is defined by the orientation tensor $\underline{\underline{a}}^{\psi}$, which is diagonal in material axis $\underline{u}_{i}$, with eigenvalues $a_{i}$. One can therefore consider the material as orthotropic is material axis, with $a_{i}$ standing for the fraction of fibres aligned along the direction $\underline{u}_{i}$. Tensor 
$\mathbb{M}$ may thus be written in the general case :

$$
\mathbb{M}\left(\underline{\underline{a}}^{\psi}\right)=a_{1} \mathbb{M}_{1}+a_{2} \mathbb{M}_{2}+a_{3} \mathbb{M}_{3}
$$

$\mathbb{M}_{i}$ is the symmetric fourth-order tensor associated with unidirectional microstructure along $\underline{u}_{i}$, which reads for example:

$$
\mathbb{M}_{1}=\left[\begin{array}{cccccc}
\frac{1}{\sigma_{\text {longi }}} & \frac{-0.5}{\sigma_{\text {longi }}} & \frac{-0.5}{\sigma_{\text {longi }}} & 0 & 0 & 0 \\
& \frac{1}{\sigma_{\text {transv }}} & \frac{0.5}{\sigma_{\text {longi }}}-\frac{1}{\sigma_{\text {transv }}} & 0 & 0 & 0 \\
& & \frac{1}{\sigma_{\text {transv }}} & 0 & 0 & 0 \\
& & & \frac{2}{\tau_{\text {longi }}} & 0 & 0 \\
& & & & \frac{2}{\tau_{\text {longi }}} & 0 \\
& & & & & \frac{2}{\tau_{\text {transv }}}
\end{array}\right]_{\left(\underline{u}_{i}\right)}
$$

$\mathbb{M}_{2}$ and $\mathbb{M}_{3}$ only differ from $\mathbb{M}_{1}$ by rotations: they involve the same parameters $\sigma_{\text {longi }}, \sigma_{\text {transv }}$ and $\tau_{\text {longi. }}$. At last, in our case, the identification process leads to very high values for $\tau_{\text {transv }}$, which explains why terms involving $\frac{1}{\tau_{\text {transv }}}$ are neglected in the final expression of $\mathbb{M}$, which reads:

$$
\mathbb{M}\left(\underline{\underline{a}}^{\psi}\right)=\left[\begin{array}{cccccc}
\frac{a_{1}}{\sigma_{\text {longi }}}+\frac{a_{2}+a_{3}}{\sigma_{\text {transv }}} & \frac{0.5-a_{1}-a_{2}}{\sigma_{\text {longi }}}-\frac{a_{3}}{\sigma_{\text {transv }}} & \frac{0.5-a_{1}-a_{3}}{\sigma_{\text {longi }}}-\frac{a_{2}}{\sigma_{\text {transv }}} & 0 & 0 & 0 \\
& \frac{a_{2}}{\sigma_{\text {longi }}}+\frac{a_{1}+a_{3}}{\sigma_{\text {transv }}} & \frac{0.5-a_{2}-a_{3}}{\sigma_{\text {longi }}}-\frac{a_{1}}{\sigma_{\text {transv }}} & 0 & 0 & 0 \\
& & \frac{a_{3}}{\sigma_{\text {longi }}}+\frac{a_{1}+a_{2}}{\sigma_{\text {transv }}} & 0 & 0 & 0 \\
& & & 2 \frac{a_{1}+a_{2}}{\tau_{\text {longi }}} & 0 & 0 \\
& & & & 2 \frac{a_{1}+a_{3}}{\tau_{\text {longi }}} & 0 \\
& \text { sym } & & & 2 \frac{a_{2}+a_{3}}{\tau_{\text {longi }}}
\end{array}\right]_{\left(\underline{u}_{i}\right)}
$$

In the material axis, the stress tensor is written: $\underline{\underline{\sigma}}={ }^{t}\left\{\bar{\sigma}_{11} \bar{\sigma}_{22} \bar{\sigma}_{33} \bar{\sigma}_{12} \bar{\sigma}_{13} \bar{\sigma}_{23}\right\}_{\left(\underline{u}_{i}\right)}$. The expression of $\mathbb{M}\left(\underline{\underline{a}}^{\psi}\right)$ means that an external load $\bar{\sigma}_{11} \underline{u}_{1} \otimes \underline{u}_{1}$ corresponds to a longitudinal loading for fibres oriented along $\underline{u}_{1}$, but also to a transverse loading for fibres oriented along $\underline{u}_{2}$ and $\underline{u}_{3}$. The terms related to a shear loading $\left(\bar{\sigma}_{i j} \underline{u}_{i} \otimes \underline{u}_{j}\right.$ with $\left.i \neq j\right)$ involve the proportion of fibres oriented along $\underline{u}_{i}$ and $\underline{u}_{j}$, which are both subjected to longitudinal shear.

The proposed modified Tsai-Hill criterion is a relationship between the amplitude of $G_{\mathrm{T}-\mathrm{H}}\left(\underline{\underline{\sigma}}(t), \underline{\underline{a}}^{\psi}\right)=$ $\sqrt{\underline{\underline{\sigma}}(t): \mathbb{M}\left(\underline{\underline{a}}^{\psi}\right): \underline{\underline{\sigma}}(t)}$ and the number of cycles to failure $N_{r}$.

In the same way as for shear-stress criteria (see Eq. 9), this amplitude has to be consistent with a multiaxial formulation, which is the reason why the following definition is adopted:

$$
G_{\mathrm{T}-\mathrm{H}}^{a}=\min _{\underline{\underline{\sigma}}_{1}} \max _{t \in\left[0, T_{\text {cycle }}\right]}\left[\sqrt{\left(\underline{\underline{\sigma}}_{1}-\underline{\underline{\sigma}}(t)\right): \mathbb{M}\left(\underline{\underline{a}}^{\psi}\right):\left(\underline{\underline{\sigma}}_{1}-\underline{\underline{\sigma}}(t)\right)}\right]
$$

The proposed modified Tsai-Hill criterion for the fatigue life duration of SGFR thermoplastics is then formulated as:

$$
G_{\mathrm{T}-\mathrm{H}}^{a} \cdot N_{r}^{b}=1
$$


It requires the identification of four model parameters $\sigma_{\text {longi }}, \sigma_{\text {transv }}, \tau_{\text {longi }}$ and the slope $b$, provided that the orientation tensor $\underline{a}^{\psi}$ is known. A priori, these four parameters are supposed to be dependent on temperature and relative humidity.

\section{References}

[1] Launay, A., Maitournam, M., Marco, Y., Raoult, I.. Multiaxial fatigue models for short glass fiber reinforced polyamide. Part I: Nonlinear anisotropic constitutive behaviour for cyclic response. International Journal of Fatigue 2012; (in press), available online, ISSN 0142-1123, DOI: 10.1016/j.ijfatigue.2012.03.012.

[2] Klimkeit, B.. Etude expérimentale et modélisation du comportement en fatigue multiaxiale d'un polymère renforcé pour application automobile. Ph.D. Thesis; École Nationale Supérieure de Mécanique et d'Aérotechnique; 2009.

[3] Klimkeit, B., Nadot, Y., Castagnet, S., Nadot-Martin, C., Dumas, C., Bergamo, S., et al. Multiaxial fatigue life assessment for reinforced polymers. International Journal of Fatigue 2011;33:766-80.

[4] De Monte, M., Moosbugger, E., Jasckek, K., Quaresimin, M.. Multiaxial fatigue of a short fibre reinforced polyamide 6.6 - Fatigue and fracture behaviour. International Journal of Fatigue 2010;32:17-28.

[5] Horst, J., Spoormaker, J.. Mecanisms of fatigue in short glass fiber reinforced polyamide 6. Polymer Engineering and Science 1996;36:2718-26.

[6] Horst, J., Spoormaker, J.. Fatigue fracture mechanisms and fractography of short-glass-fibre-reinforced polyamide 6. Journal of Materials Science 1997;32(14):3641-3651.

[7] Noda, K., Takahara, A., Kajiyama, T.. Fatigue failure mechanisms of short glass-fiber reinforced nylon 66 based on nonlinear dynamic viscoelastic measurement. Polymer 2001;42(13):5803-5811.

[8] Nouri, H., Meraghni, F., Lory, P.. Fatigue damage model for injection-molded short glass fibre reinforced thermoplastics. International Journal of Fatigue 2009;31(5):934-942.

[9] Horst, J., Salienko, N., Spoormaker, J.. Fibre-matrix debonding stress analysis for short fibre-reinforced materials with matrix plasticity, finite element modelling and experimental verification. Composites Part A 1998;29(5-6):525-531.

[10] Mourglia Seignobos, E.. Compréhension des mécanismes physiques de fatigue dans le polyamide vierge et renforcé de fibres de verre. Ph.D. Thesis; INSA de Lyon; 2009.

[11] De Monte, M., Moosbugger, E., Quaresimin, M.. Influence of temperature and thickness on the off-axis behaviour of short glass fibre reinforced polyamide 6.6 - cyclic loading. Composites: Part A 2010;41:1368-79.

[12] Bernasconi, A., Davoli, P., Rossin, D., Armanni, C.. Effect of reprocessing on the fatigue strength of a fibreglass reinforced polyamide. Composites Part A 2007;38(3):710-718.

[13] Zago, A., Springer, G.. Constant Amplitude Fatigue of Short Glass and Carbon Fiber Reinforced Thermoplastics. Journal of Reinforced Plastics and Composites 2001;20(7):564.

[14] Mallick, P., Zhou, Y.. Effect of mean stress on the stress-controlled fatigue of a short E-glass fiber reinforced polyamide-6, 6. International Journal of Fatigue 2004;26(9):941-946.

[15] Bernasconi, A., Davoli, P., Basile, A., Filippi, A.. Effect of fibre orientation on the fatigue behaviour of a short glass fibre reinforced polyamide-6. International Journal of Fatigue 2007;29(2):199-208.

[16] Barbouchi, S., Bellenger, V., Tcharkhtchi, A., Castaing, P., Jollivet, T.. Effect of water on the fatigue behaviour of a PA66/glass fibers composite material. Journal of Materials Science 2007;42:2181-2188.

[17] Handa, K., Kato, A., Narisawa, I.. Fatigue Characteristics of a Glass-Fiber-Reinforced Polyamide. Journal of Applied Polymer Science 1999;72:1783-1793.

[18] Launay, A., Marco, Y., Maitournam, M., Raoult, I.. Influence of temperature and relative humidity on the cyclic behaviour of a short glass fibre reinforced polyamide. Mechanics of Materials 2012; accepted for publication. 
[19] Jia, N., Kagan, V.. Effects of Time and Temperature on the Tension-Tension Fatigue Behavior of Short Fiber Reinforced Polyamides. Polymer Composites 1998;19(4):408-414.

[20] Lang, R., Manson, J., Hertzberg, R.. Mechanisms of fatigue fracture in short glass fibre-reinforced polymers. Journal of Materials Science 1987;22(11):4015-4030.

[21] Lang, R., Manson, J.. Crack tip heating in short-fibre composites under fatigue loading conditions. Journal of Materials Science 1987;22(10):3576-3580.

[22] Herman, W., Hertzberg, R., Manson, J.. The influence of loading history on fatigue in engineering plastics. Journal of Materials Science 1990;25(1):434-440.

[23] Bellenger, V., Tcharkhtchi, A., Castaing, P.. Thermal and mechanical fatigue of a PA66/glass fibers composite material. International Journal of Fatigue 2006;28(10):1348-1352.

[24] Casado, J., Carrascal, I., Polanco, J., Gutiérrez-Solana, F.. Fatigue failure of short glass fibre reinforced PA 6.6 structural pieces for railway track fasteners. Engineering Failure Analysis 2006;13(2):182-197.

[25] Hertzberg, R., Manson, J., Skibo, M.. Frequency sensitivity of fatigue processes in polymeric solids. Polymer Engineering and Science 1975;15(4):252-260.

[26] Sonsino, C., Moosbrugger, E.. Fatigue design of highly loaded short-glass-fibre reinforced polyamide parts in engine compartments. International Journal of Fatigue 2008;30(7):1279-1288.

[27] Zago, A., Springer, G.. Fatigue Lives of Short Fiber Reinforced Thermoplastics Parts. Journal of Reinforced Plastics and Composites 2001;20(7):606.

[28] Gaier, C., Unger, B., Dannbauer, H.. Multiaxial fatigue analysis of orthotropic materials. Revue de Métallurgie 2010;107(9):369-375.

[29] Kujawski, D., Ellyin, F.. A unified approach to mean stress effect on fatigue threshold conditions. International Journal of Fatigue 1995;17(2):101-106.

[30] De Monte, M., Moosbugger, E., Quaresimin, M.. Influence of temperature and thickness on the off-axis behaviour of short glass fibre reinforced polyamide 6.6 - Quasi-static loading. Composites: Part A 2010;41:859-71.

[31] Launay, A., Marco, Y., Maitournam, M., Raoult, I.. Constitutive behavior of injection molded short glass fiber reinforced thermoplastics: a phenomenological approach. Procedia Engineering 2011;10:2003-8.

[32] Klimkeit, B., Castagnet, S., Nadot, Y., El Habib, A., Benoit, G., Bergamo, S., et al. Fatigue damage mechanisms in short fiber reinforced PBT+PET GF30. Mechanical Science and Engineering A 2011;528:1577-88.

[33] Launay, A., Maitournam, M., Marco, Y., Raoult, I., Szmytka, F.. Cyclic behavior of short glass fiber reinforced polyamide: experimental study and constitutive equations. International Journal of Plasticity 2011;27:1267-93.

[34] Benoit, A., Maitournam, M., Rémy, L., Oger, F.. Cyclic behaviour of structures under thermomechanical loadings: application to exhaust manifolds. International Journal of Fatigue 2012;38(0):65-74.

[35] Ambrico, J., Begley, M.. Plasticity in fretting contact. Journal of the Mechanics and Physics of Solids 2000;48(11):23912417.

[36] Constantinescu, A., Dang Van, K., Maitournam, M.. A unified approach for high and low cycle fatigue based on shakedown concepts. Fatigue \& Fracture of Engineering Materials \& Structures 2003;26(6):561-568.

[37] Jabbado, M., Maitournam, M.. A high-cycle fatigue life model for variable amplitude multiaxial loading. Fatigue \& Fracture of Engineering Materials \& Structures 2008;31(1):67-75.

[38] Maitournam, M., Krebs, C., Galtier, A.. A multiscale fatigue life model for complex cyclic multiaxial loading. International Journal of Fatigue 2011;33(2):232-240.

[39] Papadopoulos, I., Davoli, P., Gorla, C., Filippini, M., Bernasconi, A.. A comparative study of multiaxial high-cycle fatigue criteria for metals. International Journal of Fatigue 1997;19(3):219-235.

[40] Dang Van, K., Bignonnet, A., Fayard, J., Janosch, J.. Assessment of welded structures by a local multiaxial fatigue 
approach. Fatigue \& Fracture of Engineering Materials \& Structures 2001;24(5):369-376.

[41] Fares, Y., Chaussumier, M., Daidié, A., Guillot, J.. Determining the life cycle of bolts using a local approach and the Dang Van criterion. Fatigue \& Fracture of Engineering Materials \& Structures 2006;29(8):588-596.

[42] Hill, R.. A theory of the yielding and plastic flow of anisotropic metals. Proceedings of the Royal Society of London Series A, Mathematical and Physical Sciences 1948;193(1033):281-297.

[43] Manson, S.. Behaviour of materials under conditions of thermal stress. NACA Technical Report No 2933 1953;1170:317350.

[44] Coffin, L.. A study of the effects of cyclic thermal stresses on a ductile material. Trans ASME 1954;76:931-950.

[45] Morrow, J.D.. Cyclic plastic strain energy and fatigue of metals. American Society of Testing Materials $1965 ;: 45-87$.

[46] Skelton, R.P.. Energy criterion for high temperature low cycle fatigue. Material Science and Technology 1991;7(5):427-440.

[47] Charkaluk, E., Constantinescu, A.. An energetic approach in thermomechanical fatigue for silicon molybdenum cast iron. Materials at High Temperatures 2000;17(3):373-380.

[48] Amiable, S., Chapuliot, S., Constantinescu, A., Fissolo, A.. A comparison of lifetime prediction methods for a thermal fatigue experiment. International Journal of Fatigue 2006;28(7):692-706.

[49] Quaresimin, M., Susmel, L., Talreja, R.. Fatigue behaviour and life assessment of composite laminates under multiaxial loadings. International Journal of Fatigue 2010;32(1):2-16.

[50] Jen, M., Lee, C.. Strength and life in thermoplastic composite laminates under static and fatigue loads. part i: Experimental. International Journal of Fatigue 1998;20(9):605-615.

[51] Jen, M., Lee, C.. Strength and life in thermoplastic composite laminates under static and fatigue loads. part ii: Formulation. International Journal of Fatigue 1998;20(9):617-629.

[52] Degrieck, J., Van Paepegem, W.. Fatigue damage modeling of fibre-reinforced composite materials: Review. Applied Mechanics Reviews 2001;54:279.

[53] Poncelet, M., Doudard, C., Calloch, S., Weber, B., Hild, F.. Probabilistic multiscale models and measurements of self-heating under multiaxial high cycle fatigue. Journal of the Mechanics and Physics of Solids 2010;58(4):578-593.

[54] Tsai, S., Wu, E.. A general theory of strength for anisotropic materials. Journal of Composite Materials 1971;5(1):58.

[55] Hashin, Z.. Failure Criteria for Unidirectional Fiber Composites. Journal of Applied Mechanics 1980;47:329.

[56] Sims, D., Brogdon, V.. Fatigue behavior of composites under different loading modes. Fatigue of filamentary composite materials 1977;636:185-205.

[57] Kawai, M., Hachinohe, A., Takumida, K., Kawase, Y.. Off-axis fatigue behaviour and its damage mechanics modelling for unidirectional fibre-metal hybrid composite: Glare 2. Composites Part A 2001;32(1):13-23. 